\title{
Synthesis and nanoscale characterization of hierarchically assembled molecular nanosheets
}

\author{
Marie Richard-Lacroix, ${ }^{1,2 \otimes^{*}}$ Maria Küllmer ${ }^{1 \otimes}$ Anna Laurine Gaus, ${ }^{3}$ Christof Neumann, ${ }^{1}$ \\ Christian Tontsch, ${ }^{3}$ Max von Delius, ${ }^{3 *}$ Volker Deckert ${ }^{1,2,4,6^{*}}$, Andrey Turchanin ${ }^{1,5,6^{*}}$ \\ ${ }^{1}$ Institute of Physical Chemistry and Abbe Center of Photonics, Friedrich Schiller University \\ Jena, 07743 Jena, Germany \\ ${ }^{2}$ Leibniz Institute of Photonic Technology, 07745 Jena, Germany \\ ${ }^{3}$ Institute of Organic Chemistry, Ulm University, 89081 Ulm, Germany \\ ${ }^{4}$ Institute of Quantum Science and Engineering, Texas A\&M University, \\ College Station, TX 77843, USA \\ ${ }^{5}$ Center for Energy and Environmental Chemistry Jena (CEEC Jena), 07743 Jena, Germany \\ ${ }^{6} J e n a$ Center for Soft Matter (JCSM), 07743 Jena, Germany
}

\footnotetext{
${ }^{\otimes}$ These authors contributed equally to this work

Corresponding authors:

marie.richard-lacroix@uni-jena.de

max.vondelius@uni-ulm.de

volker.deckert@uni-jena.de

andrey.turchanin@uni-jena.de
} 


\begin{abstract}
Chemical functionalization of molecular two-dimensional (2D) materials towards the assembly of hierarchical functional nanostructures is of great importance for nanotechnology including areas like artificial photocatalytic systems, nanobiosensors or ultrafiltration. To achieve the desired functionality of $2 \mathrm{D}$ materials, these need to be characterized down to the nanoscale. However, obtaining the respective chemical information is challenging and generally requires the application of complementary experimental techniques. Here, we demonstrate the synthesis and chemical characterization of hierarchically assembled molecular nanosheets based on $\sim 1 \mathrm{~nm}$ thin, molecular carbon nanomembrane (CNM) and covalently grafted, single-molecule layer cobalt(III) catalysts for the light-driven hydrogen evolution reaction (HER). We employ X-ray photoelectron spectroscopy (XPS) and tip-enhanced Raman spectroscopy (TERS) to access both the transversal and lateral chemical information of the synthesized nanosheets with nanometer resolution. TERS and XPS data provide detailed information on the average and local surface distribution of the catalyst as well as mechanistic details of the grafting reaction. The proposed approach represents a general route towards a nanoscale structural analysis for a variety of molecular $2 \mathrm{D}$ materials $-\mathrm{a}$ rapidly growing materials class with broad prospects for fundamental science and applications.
\end{abstract}

Keywords: molecular nanosheets, chemical functionalization, hierarchical assembly, tip-enhanced Raman spectroscopy 


\section{TOC image}

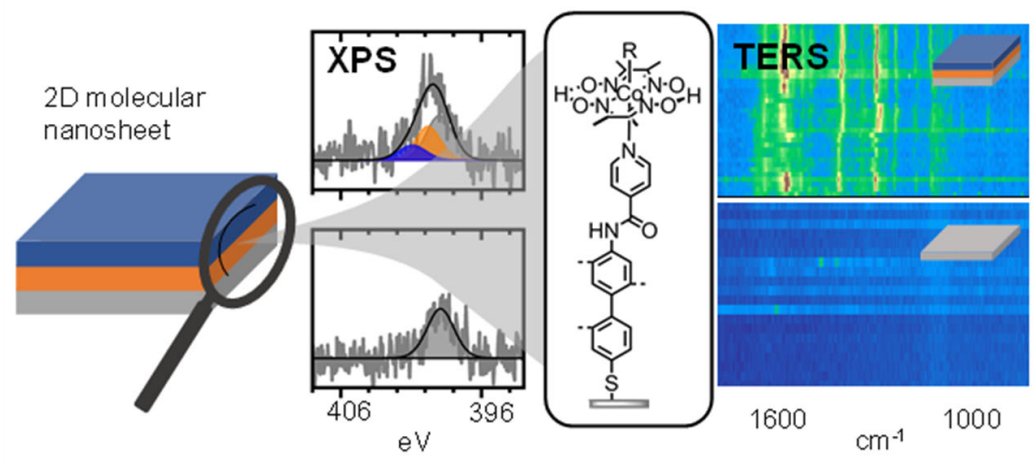

\section{TOC text}

Hierarchically assembled nanosheets with ultimate molecular thickness, bearing functional cobalt(III) complexes are investigated by X-ray photoelectron spectroscopy and tip-enhanced Raman scattering. The combination of both techniques provides detailed insights into the structure of the formed 2D materials down to the nanoscale. 


\section{Introduction}

The assembly of two-dimensional (2D) hierarchical structures is a promising route for creating functional nanomaterials with nanoscale control and tunability. ${ }^{[1,2]}$ These nanostructures find applications in various areas like sensor technology, ${ }^{[3-6]}$ energy storage and conversion, ${ }^{[7-12]}$ catalysis, ${ }^{[13,14]}$ as well as optical and optoelectronic devices. ${ }^{[15]}$ One of the main challenges in their synthesis is the tailored incorporation of chemical functional units. 2D carbon materials such as graphene have attracted an enormous interest in this respect. ${ }^{[16,17]}$ However, the use of graphene, as a platform for the assembly of hierarchical materials is limited, in particular due to its chemical inertness and deterioration of its physical properties upon functionalization. ${ }^{[15,18,19]}$ Therefore, molecular nanosheets shift more and more into focus, as they can be assembled flexibly from various organic compounds and intrinsically provide functional groups. ${ }^{[20,21]}$ In this respect carbon nanomembranes $(\mathrm{CNM})-$ molecular nanosheets with $\sim 1 \mathrm{~nm}$ thickness, deliver a universal platform for the hierarchical assembly of 2D materials. ${ }^{[22-25]}$ CNMs can be synthesized by electron irradiation induced cross-linking of aromatic self-assembled monolayers (SAMs) on a large scale, ${ }^{[23]}$ with tunable thickness ${ }^{[24]}$ and porosity ${ }^{[24,26]}$ and allow chemical functionalization ${ }^{[27,28]}$ as well as gas and ion permeation ${ }^{[29,30]}$, etc. Examples for the employment of CNMs are the hierarchical assembly of $2 \mathrm{D}$ sheets for bio-recognition ${ }^{[31]}$ and energy-funneling ${ }^{[27]}$ applications as well as for implementation of organic-inorganic hybrids ${ }^{[32]}$. The distribution and orientation of active sites down to nanometer dimensions is of crucial importance for all applications and needs to be characterized in detail consequently.

In this work, we employ the inherent properties of CNMs, specifically their chemical and mechanical robustness as well as their ability for flexible surface functionalization, to assemble molecular catalysts for hydrogen evolution reaction (HER) on their surfaces. We use CNMs made by cross-linking of $4^{\prime}$-nitro-1,1'-biphenyl-4-thiol (NBPT) SAMs on gold ${ }^{[33-35]}$ and the cobalt (III) dimethylglyoxime $(\mathrm{dmgH})^{[36]}$ double complex salt $\left[\mathrm{Co}(\mathrm{dmgH})_{2}(\mathrm{py})_{2}\right]^{+}\left[\mathrm{Co}(\mathrm{dmgH})_{2} \mathrm{Cl}_{2}\right]^{-}$(from here on $\mathrm{Co}^{+} \mathrm{Co}^{-}$). For structures see Supporting Information (SI). ${ }^{[37]}$ This type of molecular catalyst for the light-driven HER has emerged ${ }^{[38-41]}$ as a promising alternative to noble metal catalysts (e.g., based on platinum). By strategically synthesizing ${ }^{[42]}$ and making use of the double complex salt $\left[\mathrm{Co}(\mathrm{dmgH})_{2}(\mathrm{py})_{2}\right]^{+}\left[\mathrm{Co}(\mathrm{dmgH})_{2} \mathrm{Cl}_{2}\right]^{-}$rather than the neutral complex $\left[\mathrm{Co}(\mathrm{dmgH})_{2}(\mathrm{py}) \mathrm{Cl}\right]^{[43]}$, we were able to investigate the immobilization behaviour of negatively and positively charged 
complex ions at the same time. We use a combination of X-ray photoelectron spectroscopy (XPS - Figure 1a) as a surface sensitive tool for the transversal chemical information and tip-enhanced Raman spectroscopy (TERS - Figure 1b) to obtain the lateral chemical information during the stepwise assembly of this hierarchically constructed molecular nanosheet. This combined analytical approach of XPS, as a classical surface sensitive technique, and TERS, as a powerful tool for 2D material nanoscale characterization, ${ }^{[44,45]}$ enabled us to achieve detailed structural and chemical information of the molecular catalyst spatial distribution, their surface number density and the involved axial ligands. Employing the scanning capabilities of atomic force spectroscopy (AFM), chemical specificity of Raman spectroscopy and plasmonic activity to spatially enhance and localize the field, TERS facilitates probing the presence of species at the surface with nanometer scale precision (Figure $1 \mathrm{~b}$ ) and high signal-to-noise ratio. ${ }^{[46]}$ In particular, the exceptionally high scattering cross section of the molecular catalyst yields high quality TERS data. In this way detailed information of the surface distribution and integrity of the respective compounds are provided at every step of the synthesis ultimately allowing efficient synthesis and property optimization of the functional, ultrathin material.

\section{Results and Discussion}

The nanosheets assembly is schematically presented in Figure 1c-e. First, we convert 4 ' -nitro1,1'-biphenyl-4-thiol (NBPT) SAMs on a gold substrate into short-range ordered $\mathrm{NH}_{2}$-CNMs (Figure 1c) via low-energy electron irradiation induced cross-linking. Next, isonicotinic acid is covalently bound to the CNMs amino groups employing active esters for amide bond formation (iso-CNM, Figure 1d). Finally, these pyridine derivatives can act as axial ligands for $\mathrm{Co}^{+} \mathrm{Co}^{-}$double salt ions and exchange against their initial pyridine or chloride ligands (Co(III)-CNM, Figure 1e). The details of the Co(III) catalyst synthesis and 2D nanosheet preparation procedure are given in section S1 and Figures S1-6 of the SI. Below we characterize in detail this hierarchical assembly of the nanosheets at every preparation step by XPS and TERS.

\subsection{XPS}

The high-resolution $\mathrm{C} 1 \mathrm{~s}$ and $\mathrm{N} 1 \mathrm{~s}$ XP spectra of the $\mathrm{NH}_{2}-\mathrm{CNM}$ are shown in the first row of Figure 2. The $\mathrm{C} 1 \mathrm{~s}$ peak is represented by four components with different binding energies (BEs) 


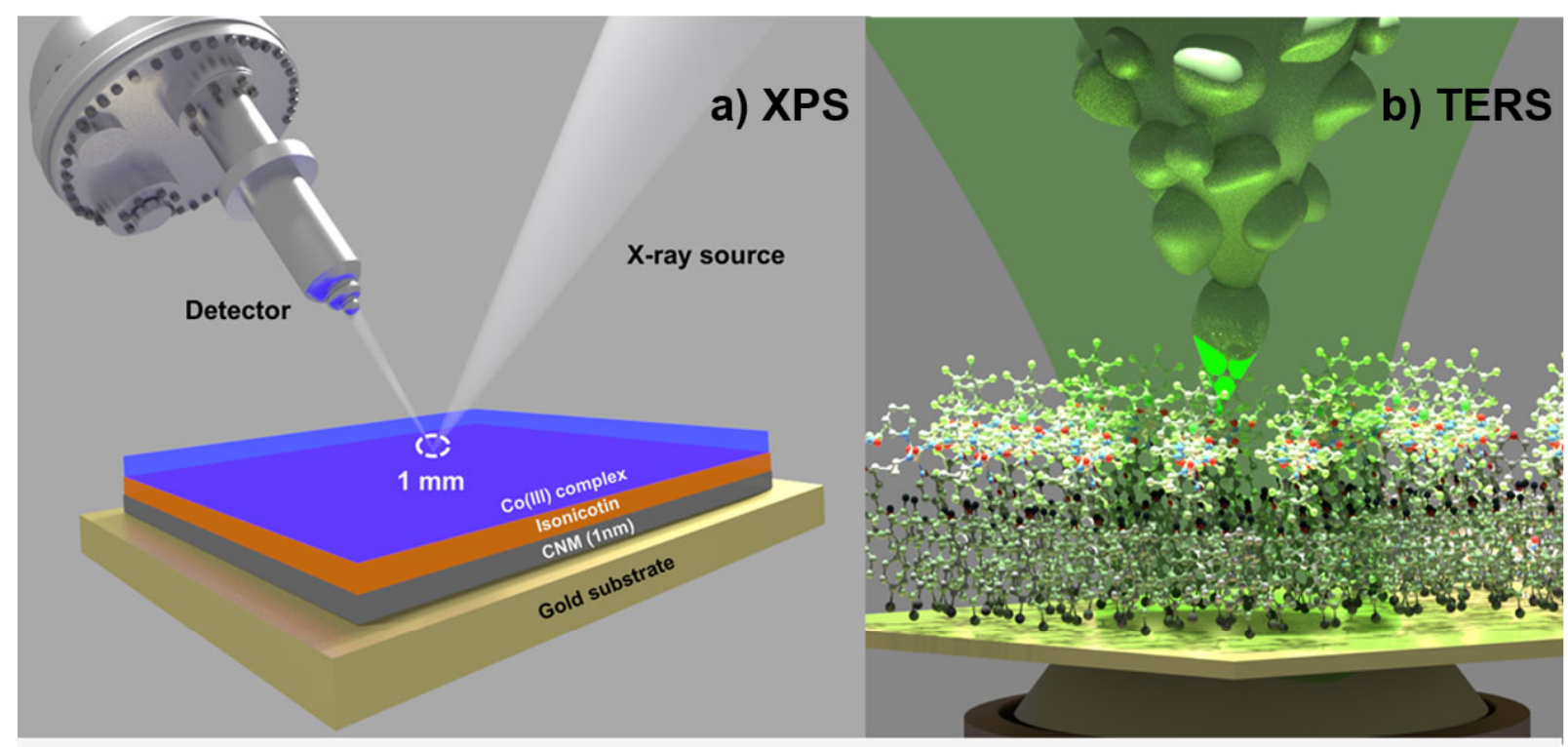

c) $\mathrm{NH}_{2}-\mathrm{CNM}$

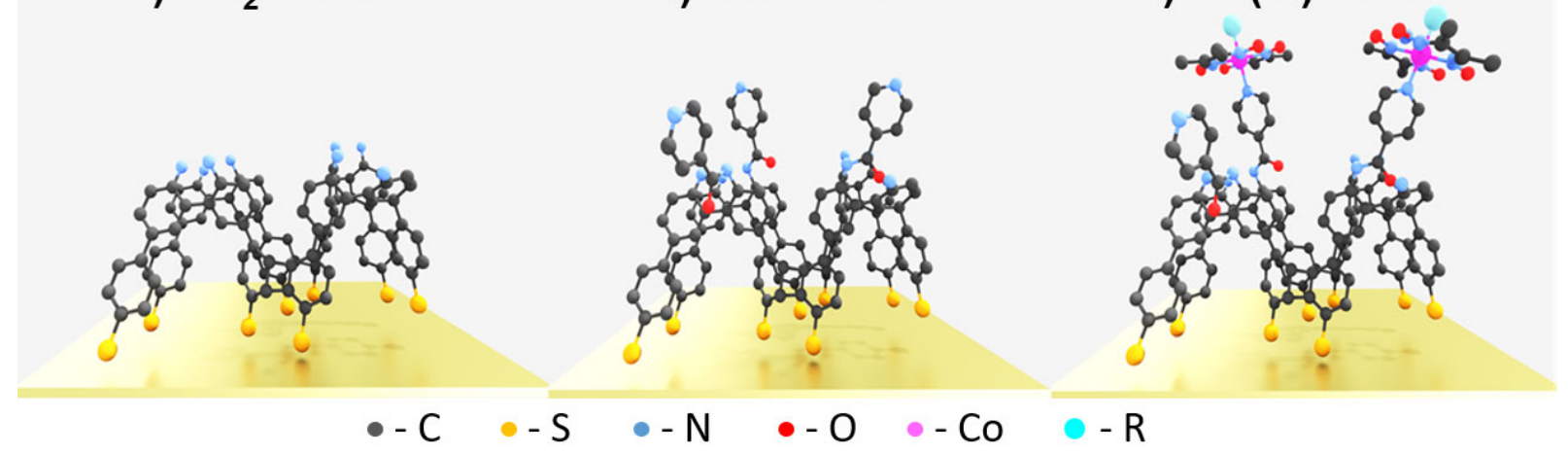

Figure 1. Schematic representation a) and b) of XPS and TERS i.e. surface sensitivity $v$ s. lateral resolution. In the configuration used in this study, the XPS analysis area is on the order of $1 \mathrm{~mm}$ (white circle in a)) providing the nanoscale resolution in to the depth of the sample, while TERS probes nanoscale dimensions in terms of the lateral resolution (light green at the apex of the TERS tip, in b). c) $\mathrm{NH}_{2}$-CNM produced by the cross-linking of 4'-nitro-4,4'-biphenyl-4-thiol (NBPT) SAM via low-energy electron irradiation. d) $\mathrm{NH}_{2}-\mathrm{CNM}$ functionalized with isonicotinic acid through the formation of a covalent amide bond (iso-CNM), where in e) the terminal pyridine groups allow axial ligand exchange with the complex salt $\left[\mathrm{Co}(\mathrm{dmgH})_{2}(\mathrm{py})_{2}\right]^{+}\left[\mathrm{Co}(\mathrm{dmgH})_{2} \mathrm{Cl}_{2}\right]^{-}$to immobilize $\mathrm{Co}(\mathrm{III})$ centers on the nanomembrane (Co(III)-CNM). Hydrogen atoms are not depicted in c)-d) for simplicity. 


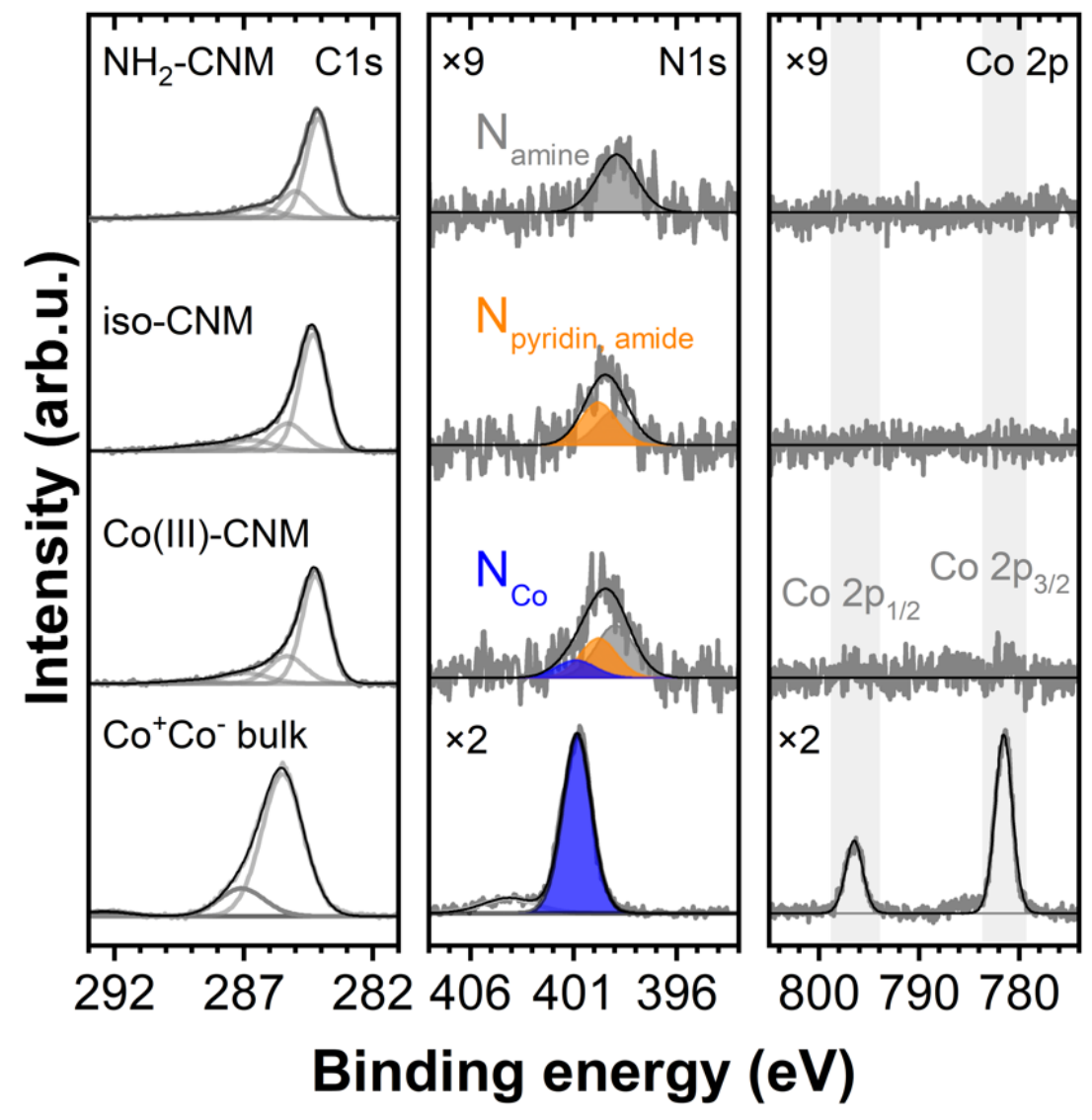

Figure 2. XP spectra acquired from the samples represented in Figure 1c), d) and e) in comparison to a drop casted reference $\mathrm{Co}^{+} \mathrm{Co}-{ }^{-}$sample. The $\mathrm{C} 1 \mathrm{~s}$ (left panel), N 1s (middle panel) and Co 2p (right panel) binding energy spectral ranges are shown (for better visibility $\mathrm{N} 1 \mathrm{~s}$ and Co $2 \mathrm{p}$ are scaled by the indicated factors). Grey, orange and blue fitted bands are associated to the amino group of the $\mathrm{CNM}$, the isonicotine moiety and to the $\mathrm{Co}^{+} \mathrm{Co}^{-}$double salt complex, respectively. 
assigned to C-C (284.1 eV), C-N/C-S bonds (BE $285.0 \mathrm{eV})$ and aromatic shake-up satellites (286.4 and $288.6 \mathrm{eV}$ ). ${ }^{[31,47]}$ The $\mathrm{N} 1 \mathrm{~s}$ peak at $398.9 \mathrm{eV}$ (grey) corresponds to the terminal amino groups ${ }^{[31 \text {, }}$ ${ }^{47]}$ ( $c f$. Figure 1c). As expected, no Co $2 p$ signals are observed in the respective BE range. The S $2 \mathrm{p}$ XP spectrum presented in Figure S7 shows thiolates as well as disulfides or thiols formed upon the electron irradiation. ${ }^{[25,48]}$ Spectroscopic details including full width at half maximum (FWHM) values of the individual peaks and relative intensity ratios of their components are presented in Table S1 of the SI.

The coupling of isonicotinic acid to the amino groups of $\mathrm{NH}_{2}-\mathrm{CNM}$ (iso-CNM, second row in Figure 2) is reflected in the $\mathrm{C} 1 \mathrm{~s}$ region by increasing intensities at the BEs of $284.3 \mathrm{eV}, 285.3$ and $288.6 \mathrm{eV}$ due to the pyridine carbon atoms ${ }^{[49]}$ and the amide carbonyl group ${ }^{[50]}$, respectively. In the $\mathrm{N} 1 \mathrm{~s}$ spectrum an additional component at $399.8 \mathrm{eV}$ (orange) appears which confirms the isonicotinic acid attachment via formation of the amide and pyridine nitrogen species. ${ }^{[49,50]}$ The $\mathrm{Co}(\mathrm{III})-\mathrm{CNMs} \mathrm{XP}$ spectra are analyzed by comparing them with the $\mathrm{Co}^{+} \mathrm{Co}^{-}$reference bulk spectra (bottom row in Figure 2) as well as to the XP spectra of the iso-CNM. The C 1s components of the $\mathrm{Co}^{+} \mathrm{Co}^{-}$reference appear at the BEs of $285.5 \mathrm{eV}$ and $287.1 \mathrm{eV}$, which result from the pyridine and $\mathrm{dmgH}$ ligands of the Co(III) ion ${ }^{[51]}$. As seen from Figure 2, the iso-CNMs C 1s peaks overlap with these components leading therefore only to slight increase of the intensity in the respective $\mathrm{BE}$ region upon the complex attachment to the iso-CNM. The $\mathrm{N}$ 1s spectrum in the formed $\mathrm{Co}(\mathrm{III})-$ CNM can be deconvoluted into three components. Similar as for the iso-CNM the grey and orange components are present at $399.0 \mathrm{eV}$ and $399.8 \mathrm{eV}$ and assigned to unmodified amines and isonicotine moieties, respectively. Besides these XP peaks also a small shoulder (blue) occurs at the $\mathrm{BE}$ of $400.9 \mathrm{eV}$. As this $\mathrm{BE}$ is in agreement with the $\mathrm{BE}$ of nitrogen in the $\mathrm{Co}^{+} \mathrm{Co}^{-}$reference $\left(\mathrm{BE} 400.8 \mathrm{eV}\right.$ ) and literature data ${ }^{[51,52]}$, we assign this component to the attachment of the Co(III) complex. Although the reference sample clearly shows the presence of Co(III) ions (Co 2p $3 / 2781.5$ $\mathrm{eV}$, Co $2 \mathrm{p}_{1 / 2} 796.5 \mathrm{eV}$ ), intensity in the BE range of the Co $2 p$ signal for the Co(III)-CNM is on the experimental noise level. The same applies for the $\mathrm{Cl} 2 \mathrm{p}$ signal that would be expected to result from the presence of one remaining axial chloride ligand upon immobilization of the $\mathrm{Co}^{-}$anion (see Figure S8). ${ }^{[51]}$ Based on model calculations of the XPS Co 2p detection limit (section S2.2 of the SI and also Figures S9 and S10), we propose that the lack of observation of significant Co $2 p$ and $\mathrm{Cl} 2 \mathrm{p}$ signals by XPS is due to a sub-monolayer coverage of the complexes on top of the CNM (vide infra for TERS results on these two elements). 
Next, based on changes of the $\mathrm{N}$ 1s signal upon attachment of the isonicotines and Co(III) complexes to the $\mathrm{NH}_{2}-\mathrm{CNM}$, we estimate functionalization degree of the amino groups, surface number density of the complexes as well as the average distance between them. To this end, we compare the N 1s signal intensities (grey, orange and blue in Figure 2; see also Figure S12) caused by the different molecular moieties attached to the $\mathrm{NH}_{2}-\mathrm{CNM}$ upon each functionalization step. Section S.2.3 of the SI presents the applied model calculation in detail. For this calculation, we estimated the surface number density of amino groups in the $\mathrm{NH}_{2}-\mathrm{CNM}$ based on the literature data for the surface number density of NBPT molecules in the SAM as well as partial loss of the nitrogen

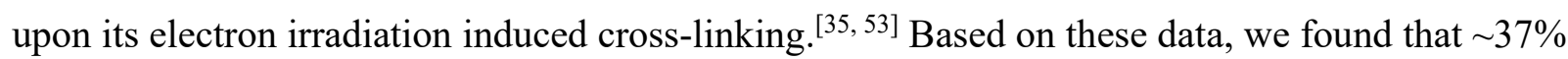
of the amino groups of $\mathrm{NH}_{2}-\mathrm{CNM}$ (Figure 1c) are functionalized with isonicotinic acid (Figure 1d), whereas the respective functionalization with $\mathrm{Co}(\mathrm{III})$ complexes (Figure 1e) is $\sim 4 \%$. This functionalization degree implies that the average complex-to-complex distance in the Co(III)-CNM is $\sim 3 \mathrm{~nm}$.

\subsection{TERS}

We conduct the TERS study to enable the lateral nanoscale characterization of the hierarchical assembly of Co(III)-CNM. To this end, CNM samples (Figure $1 \mathrm{c}$-e) were transferred onto gold coated, yet still transparent glass cover slips to allow sensitive TERS studies. ${ }^{[54]}$ These samples were characterized by XPS to assure their similar spectroscopic characteristics as reported in Section 2.1. Based on the general TERS instrument setup, the nanoscale topography is intrinsically correlated to the actual near-field Raman spectra. Figure S13 in the SI shows such a topography of a pristine CNM surface prior to TERS mapping, where the roughness of the CNM is low as expected. Figure $3 \mathrm{a}$ and $3 \mathrm{~b}$ present an example of a series of spectra measured on a $\mathrm{NH}_{2}-\mathrm{CNM}$ membrane with a point-to-point distance of $25 \mathrm{~nm}$, along with the associated waterfall plot for better clarity. This distance was chosen to provide a compromise between area coverage and lateral resolution. It should be emphasized that the lateral resolution capability of TERS has been shown to be in the order of a few Ångström. ${ }^{[55-60]}$ Consequently a $25 \mathrm{~nm}$ step size relates to a significant undersampling but allows to cover representative sample areas with reasonable acquisition times (see also section S4 of the SI). The spectra primarily show the Si signal from the AFM tip at $\sim 520$ and $1000 \mathrm{~cm}^{-1}$. In addition, spurious signals occur which were not assigned due to the low signal to noise ratio. This behavior is consistent with the surface enhanced Raman spectroscopy (SERS) 

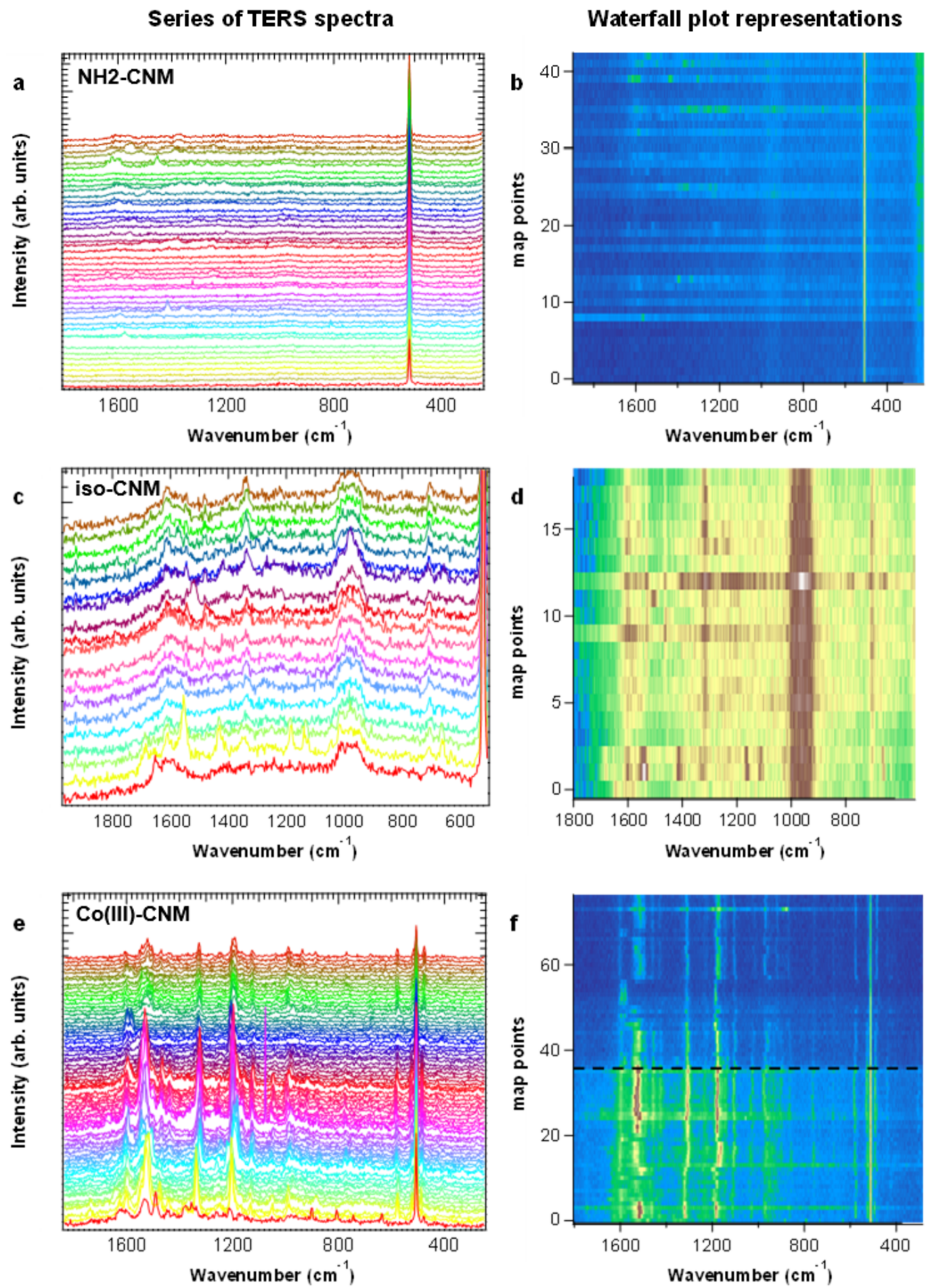

Figure 3. a) and b), c) and d), e) and f) are TERS spectra and corresponding waterfall plots of a series of measurements on $\mathrm{NH}_{2}-\mathrm{CNM}$, iso-CNM and $\mathrm{Co}$ (III)-CNM, respectively, with point-topoint distance of $25 \mathrm{~nm}$. The dashed line in $\mathrm{f}$ ) indicates a position from which the laser power was reduced. 
investigation by Zhang et al. ${ }^{[61]}$ who showed a gradual loss of Raman signal upon cross-linking of the NBPT SAM. We believe that this low signal is due to the nature of the CNM itself, which is formed from a laterally disordered carbon network ${ }^{[62]}$ that typically shows low Raman crosssections. ${ }^{[61]}$ The low Raman scattering cross section of $\mathrm{NH}_{2}-\mathrm{CNM}$ is a considerable advantage, as it allows to specifically distinguish the specific overlayers in the following experiments without interference.

Figure $3 \mathrm{c}$ and $\mathrm{d}$ show the spectra and the respective waterfall plot measured on the iso-CNM sample. While the signal-to-noise ratio is low due to the low power used to avoid burning, the experiment clearly reveals the presence of all characteristic main bands of the isonicotine moiety at $\sim 1610,1360,1000$ and $650 \mathrm{~cm}^{-1}$ consistent with SERS investigations. ${ }^{[63,64]}$ The absence of a strong $\mathrm{C}=\mathrm{O}$ stretching signal at $\sim 1650-1700 \mathrm{~cm}^{-1}$ (carboxylic group) strongly indicates that the molecules are bound covalently via an amide bond on the surface and are not simply physisorbed. In TERS, vibrational modes with contributions of the scattering tensor along the tip axis are preferentially probed. Here, the amide group is expected to be perpendicular to the tip axis and thus, a relatively minor signal enhancement as shown in Figure $3 \mathrm{c}$ is expected. ${ }^{[65]}$ Band position fluctuations and narrow bandwidths can be clearly observed in the waterfall plot of Figure $3 \mathrm{~d}$. Those features are commonly observed in TERS and indicate, only few molecules are probed at the respective tip positions. As the signal is not averaged over large molecular ensembles with slightly different orientations, the system is extremely sensitive to minute variations in the chemical environment, i.e. the relative orientation of molecules. ${ }^{[66]}$ Consequently, the spectral fluctuations observed in Figure 3 are a strong, albeit indirect, indication of the high resolution of TERS experiments. ${ }^{[67]}$ The overall similarity of the spectral positions and their intensities on the other hand suggests that a comparable number of similarly arranged molecules contributes to the respective spectra. Hence, the results point to a homogeneous distribution of isonicotinic acid over an area on the order of hundreds of nm as well as its high surface number density (see Section S4 of the SI) consistent with the previously discussed XPS analysis. In this way the high efficiency of the immobilization reaction of isonicotine on the $\mathrm{NH}_{2}-\mathrm{CNM}$ via an active ester reagent is confirmed.

The $400 \times 400 \mathrm{~nm}^{2}$ TERS mapping (with a $25 \mathrm{~nm}$ point-to-point distance) of the Co(III)-CNM is shown in Figure 3e and f. The signal-to-noise ratio of the TERS signals is surprisingly high, 
especially considering the low laser power of $100 \mu \mathrm{W}$ used for the first part of mapping, which suggests an unusually high scattering cross-section. The spectral positions of the major bands are consistent with the far-field Raman spectra and SERS spectra measured from the $\mathrm{Co}^{+} \mathrm{Co}^{-}$double complex salt drop casted on silver nanoparticles (Figure S15). One noticeable exception is the absence of a strong signal at $\sim 275-300 \mathrm{~cm}^{-1}$, which would be attributed to $\mathrm{Co}-\mathrm{Cl}$ stretching, ${ }^{[68]} \mathrm{a}$ mode oriented along the tip axis and therefore generally accessible in TERS. According to the complex structure shown in Figure 1e, the chloride ion should also be situated in close proximity to the tip. The absence of this signal therefore suggests strongly that only the $\mathrm{Co}^{+}$cation, but not the remaining $\mathrm{Cl}^{-}$ligand of a $\mathrm{Co}^{-}$ion was immobilized on the surface. We propose that this observation could be due to thermodynamic (electrostatic preference for immobilization of the $\mathrm{Co}^{+}$ cation) and/or kinetic reasons (more rapid ligand exchange of pyridine). Such a structure confirmation is important for catalysis applications as the catalytic performance of structurally closely related $\mathrm{Co}^{+}$and $\mathrm{Co}^{-}$ions is different from the $\mathrm{Co}$ (III) complex double salt in solution and upon immobilization. ${ }^{[37]}$

To confirm that the sample was not damaged by thermal effects caused by the plasmonic activity of the tip, ${ }^{[55]}$ the power was reduced after the $35^{\text {th }}$ spectrum below $10 \mu \mathrm{W}$. The resulting spectra show the same band positions and a similar spectrum to spectrum variability as the "high power" experiments. This experiment was repeated at another sample location and with a further TERS tip to ensure that they correctly reproduce the surface chemistry and the tip was not contaminated (see Figure S16 of the SI). Figure $3 \mathrm{f}$ also highlights somewhat clearer than Figure $3 \mathrm{~d}$ the narrow bandwidth and the small band position fluctuations related to high spatial resolution. Using similar arguments as for the interpretation of the isonicotine surface number density, these results clearly demonstrate that the Co(III) complexes are probed simultaneously and that the complex-tocomplex distance must be smaller than a few $\mathrm{nm}$. This conclusion is further supported by the absence of spectra analogous to that of isonicotine (Figure $3 c$ and d). Due to the exponential decay of the field amplitude in the axial direction in TERS, ${ }^{[46,69]}$ it is unlikely that the underlying layer of isonicotine moieties can be probed simultaneously with the Co(III) complex, unless the complex-to-complex distance becomes large enough to allow the tip to access the isonicotine directly, which is obviously not the case. In general, results presented in Figure 3c-f highlight the high density of the surface functionalization and of the Co(III) complex immobilization in 
accordance with the previously estimated average molecular distances from the XPS evaluation. The transfer procedure did not influence the functionalization significantly.

\section{Conclusion}

In summary, we presented the assembly and down to the nanoscale characterisation of a hierarchically assembled 2D molecular nanosheet consisting of $\sim 1 \mathrm{~nm}$ thick carbon nanomembranes $\left(\mathrm{NH}_{2}-\mathrm{CNM}\right)$ grafted with single molecule $\mathrm{Co}(\mathrm{III})$ catalysts suitable for the lightdriven hydrogen evolution reaction. Our detailed combined XPS and TERS study enabled us to confirm the successful assembly of this 2D hybrid material as both methods provided complementary information in terms of the transversal and lateral chemical structure. The Co(III)$\mathrm{CNM}$ is formed by selective ligand exchange of the cation in complex salt $\left[\mathrm{Co}(\mathrm{dmgH})_{2}(\mathrm{py})_{2}\right]^{+}\left[\mathrm{Co}(\mathrm{dmgH})_{2} \mathrm{Cl}_{2}\right]^{-}$with isonicotine moieties anchored on the $\mathrm{NH}_{2}-\mathrm{CNM}$. In this assembly, the Co(III) complexes show a high surface number density with an average complex-tocomplex distance in the nanometer range. The engineered $\mathrm{Co}(\mathrm{III})-\mathrm{CNMs}$ can be transferred flexibly from their synthesis substrates onto target substrates preserving their chemical and structural integrity. Therewith, the developed characterization and assembly methodology provides a highly attractive and robust platform for the development of novel 2D molecular nanosheet systems for fundamental studies as well as for applications in nanotechnology.

\section{Experimental Section}

All details on preparation and measurement conditions as well as model calculations can be found in the Supporting Information. Here, a brief description of the main experimental methods and materials is provided.

Preparation of $\mathrm{Co}^{+} \mathrm{Co}^{-}$complex double salt. $\left[\mathrm{Co}(\mathrm{dmgH})_{2}(\mathrm{py})_{2}\right]^{+}\left[\mathrm{Co}(\mathrm{dmgH})_{2} \mathrm{Cl}_{2}\right]^{-}\left(\mathrm{Co}^{+} \mathrm{Co}^{-}\right.$double complex salt) was prepared in $40 \%$ yield by addition of tris(pentafluorophenyl)borane to $\left[\mathrm{Co}(\mathrm{dmgH})_{2}(\mathrm{py}) \mathrm{Cl}\right]$ in acetonitrile, followed by precipitation and repeated washing of the solid. Preparation of nanosheets. First, the $\mathrm{NH}_{2}-\mathrm{CNM}$ was prepared by irradiation of NBPT SAMs on gold/mica substrates with a low-energy electron beam employing a flood gun (FG15/40 Specs, electron energy $100 \mathrm{eV}$, dose $50 \mathrm{mC} / \mathrm{cm}^{2}$, pressure $1 \times 10^{-8}$ mbar). ${ }^{[33,35]}$ The functionalization with 
isonicotinic acid (iso-CNM) was conducted immediately after cross-linking. An active ester was formed by addition of COMU to a solution of isonicotinic acid and DIPEA in DMF before the $\mathrm{NH}_{2}-\mathrm{CNM}$ was added. Finally, the iso-CNM was placed in a solution of the $\mathrm{Co}^{+} \mathrm{Co}^{-}$double complex salt in DMF to prepare Co(III)-CNM. If necessary, the CNMs were removed from the gold/mica substrate via a Poly (methyl methacrylate) (PMMA) assisted transfer and etching of the gold layer. ${ }^{[24]}$

XPS Characterization. XPS measurements were performed on the CNMs on gold/mica substrates in a UHV Multiprobe system (Scienta Omicron, base pressure $2 \times 10^{-10} \mathrm{mbar}$ ) equipped with a monochromatic $\mathrm{Al} \mathrm{K}_{\alpha} \mathrm{X}$-ray source and an electron analyzer (Argus CU, emission angle $18.7^{\circ}$ ) with a spectral resolution of $0.6 \mathrm{eV}$.

TERS Characterization. TERS measurements were conducted on CNMs transferred to ultrathin gold films on coverslips with Ag coated silicon AFM tips (Tap 190-Al-G, Budget Sensors) under excitation with a $532 \mathrm{~nm}$ laser (Cobolt 04-01 series, Hubner Photonics). The TERS setup consisted further of a Raman spectrometer with a CCD camera (SP300 and PIXIS400, Teledyne Princeton Instruments) coupled to an AFM head (NanoWizard 2, Bruker-JPK) via an inverted microscope with a $100 \times$ oil immersion objective (NA 1.30, Olympus). Typically, $400 \times 400 \mathrm{~nm}^{2}$ areas were scanned with point distances of $25 \mathrm{~nm}$.

\section{Supporting Information}

Supporting Information including additional data as well as experimental procedures are available from the Wiley Online Library or from the author.

\section{Acknowledgements}

The authors thank the Deutsche Forschungsgemeinschaft (DFG, CRC-TRR 234 "CataLight" (projects C01, B07 and Z02). Furthermore, MK, CN and AT thank the DFG for financial support within the research grants TU149/8-2 and the research infrastructure grant INST 275/25 7-1 FUGG. 


\section{References}

[1] W. J. Roth, B. Gil, W. Makowski, B. Marszalek, P. Eliášová, Chem. Soc. Rev. 2016, 45 (12), 3400.

[2] K. Jayaramulu, D. P. Dubal, B. Nagar, V. Ranc, O. Tomanec, M. Petr, K. K. R. Datta, R. Zboril, P. Gómez-Romero, R. A. Fischer, Adv. Mater. 2018, 30 (15), 1705789.

[3] I. Tokarev, S. Minko, Adv. Mater. 2009, 21 (2), 241.

[4] G. Y. Bae, S. W. Pak, D. Kim, G. Lee, D. H. Kim, Y. Chung, K. Cho, Adv. Mater. 2016, 28 (26), 5300 .

[5] F. Xiao, Y. Li, X. Zan, K. Liao, R. Xu, H. Duan, Adv. Funct. Mater. 2012, 22 (12), 2487.

[6] J. H. Lee, C. M. Warner, H.-E. Jin, E. Barnes, A. R. Poda, E. J. Perkins, S.-W. Lee, Nat. Protoc. 2017, $12(9), 1999$.

[7] Y. Li, Z.-Y. Fu, B.-L. Su, Adv. Funct. Mater. 2012, 22 (22), 4634.

[8] J. Xu, K. Wang, S.-Z. Zu, B.-H. Han, Z. Wei, ACS Nano 2010, 4 (9), 5019.

[9] S. Yin, Y. Zhang, J. Kong, C. Zou, C. M. Li, X. Lu, J. Ma, F. Y. C. Boey, X. Chen, ACS Nano 2011, 5 (5), 3831.

[10] L. Yao, Q. Wu, P. Zhang, J. Zhang, D. Wang, Y. Li, X. Ren, H. Mi, L. Deng, Z. Zheng, Adv. Mater. 2018, 30 (11), 1706054.

[11] L. Zheng, S. Han, H. Liu, P. Yu, X. Fang, Small 2016, 12 (11), 1527.

[12] C. Han, Z. Chen, N. Zhang, J. C. Colmenares, Y.-J. Xu, Adv. Funct. Mater. 2015, 25 (2), 221.

[13] Y. Zhu, L. Peng, Z. Fang, C. Yan, X. Zhang, G. Yu, Adv. Mater. 2018, 30 (15), 1706347.

[14] L. Chen, H. Jiang, H. Jiang, H. Zhang, S. Guo, Y. Hu, C. Li, Adv. Energy Mater. 2017, 7 (15), 1602782 .

[15] N. Gao, X. Fang, Chem. Rev. 2015, 115 (16), 8294.

[16] A. K. Geim, Science 2009, 324 (5934), 1530.

[17] K. S. Novoselov, V. I. Fal'ko, L. Colombo, P. R. Gellert, M. G. Schwab, K. Kim, Nature 2012, 490 (7419), 192.

[18] H. Gao, H. Duan, Biosens. Bioelectron. 2015, 65, 404.

[19] C. Backes, A. M. Abdelkader, C. Alonso, A. Andrieux-Ledier, R. Arenal, J. Azpeitia, N. Balakrishnan, L. Banszerus, J. Barjon, R. Bartali, S. Bellani, C. Berger, R. Berger, M. M. B. Ortega, C. Bernard, P. H. Beton, A. Beyer, A. Bianco, P. Bøggild, F. Bonaccorso, G. B. Barin, C. Botas, R. A. Bueno, D. Carriazo, A. Castellanos-Gomez, M. Christian, A. Ciesielski, T. Ciuk, M. T. Cole, J. Coleman, C. Coletti, L. Crema, H. Cun, D. Dasler, D. De Fazio, N. Díez, S. Drieschner, G. S. Duesberg, R. Fasel, X. Feng, A. Fina, S. Forti, C. Galiotis, G. Garberoglio, J. M. García, J. A. Garrido, M. Gibertini, A. Gölzhäuser, J. Gómez, T. Greber, F. Hauke, A. Hemmi, I. Hernandez-Rodriguez, A. Hirsch, S. A. Hodge, Y. Huttel, P. U. Jepsen, I. Jimenez, U. Kaiser, T. Kaplas, H. Kim, A. Kis, K. Papagelis, K. Kostarelos, A. 
Krajewska, K. Lee, C. Li, H. Lipsanen, A. Liscio, M. R. Lohe, A. Loiseau, L. Lombardi, M. Francisca López, O. Martin, C. Martín, L. Martínez, J. A. Martin-Gago, J. Ignacio Martínez, N. Marzari, Á. Mayoral, J. McManus, M. Melucci, J. Méndez, C. Merino, P. Merino, A. P. Meyer, E. Miniussi, V. Miseikis, N. Mishra, V. Morandi, C. Munuera, R. Muñoz, H. Nolan, L. Ortolani, A. K. Ott, I. Palacio, V. Palermo, J. Parthenios, I. Pasternak, A. Patane, M. Prato, H. Prevost, V. Prudkovskiy, N. Pugno, T. Rojo, A. Rossi, P. Ruffieux, P. Samorì, L. Schué, E. Setijadi, T. Seyller, G. Speranza, C. Stampfer, I. Stenger, W. Strupinski, Y. Svirko, S. Taioli, K. B. K. Teo, M. Testi, F. Tomarchio, M. Tortello, E. Treossi, A. Turchanin, E. Vazquez, E. Villaro, P. R. Whelan, Z. Xia, R. Yakimova, S. Yang, G. R. Yazdi, C. Yim, D. Yoon, X. Zhang, X. Zhuang, L. Colombo, A. C. Ferrari, M. Garcia-Hernandez, 2D Mater. 2020, 7 (2), 022001.

[20] R. Dong, T. Zhang, X. Feng, Chem. Rev. 2018, 118 (13), 6189.

[21] X. Li, P. Yadav, K. P. Loh, Chem. Soc. Rev. 2020, 49 (14), 4835.

[22] A. Turchanin, Chimia 2019, 73 (6), 473.

[23] A. Turchanin, A. Gölzhäuser, Adv. Mater. 2016, 28 (29), 6075.

[24] P. Angelova, H. Vieker, N.-E. Weber, D. Matei, O. Reimer, I. Meier, S. Kurasch, J. Biskupek, D. Lorbach, K. Wunderlich, L. Chen, A. Terfort, M. Klapper, K. Müllen, U. Kaiser, A. Gölzhäuser, A. Turchanin, ACS Nano 2013, 7 (8), 6489.

[25] J. Scherr, Z. Tang, M. Küllmer, S. Balser, A. S. Scholz, A. Winter, K. Parey, A. Rittner, M. Grininger, V. Zickermann, D. Rhinow, A. Terfort, A. Turchanin, ACS Nano 2020, 14 (8), 9972.

[26] C. Neumann, D. Kaiser, M. J. Mohn, M. Füser, N.-E. Weber, O. Reimer, A. Gölzhäuser, T. Weimann, A. Terfort, U. Kaiser, A. Turchanin, ACS Nano 2019, 13 (6), 7310.

[27] Z. Zheng, C. T. Nottbohm, A. Turchanin, H. Muzik, A. Beyer, M. Heilemann, M. Sauer, A. Gölzhäuser, Angew. Chem. Int. Ed. Engl. 2010, 49 (45), 8493.

[28] Z. Tang, A. George, A. Winter, D. Kaiser, C. Neumann, T. Weimann, A. Turchanin, Chem. Eur. J. 2020.

[29] Y. Yang, P. Dementyev, N. Biere, D. Emmrich, P. Stohmann, R. Korzetz, X. Zhang, A. Beyer, S. Koch, D. Anselmetti, A. Gölzhäuser, ACS Nano 2018, 12 (5), 4695.

[30] P. M. G. van Deursen, Z. Tang, A. Winter, M. J. Mohn, U. Kaiser, A. A. Turchanin, G. F. Schneider, Nanoscale 2019, 11 (43), 20785.

[31] A. Turchanin, A. Tinazli, M. El-Desawy, H. Großmann, M. Schnietz, H. H. Solak, R. Tampé, A. Gölzhäuser, Adv. Mater. 2008, 20 (3), 471.

[32] Z. Zheng, X. Zhang, C. Neumann, D. Emmrich, A. Winter, H. Vieker, W. Liu, M. Lensen, A. Gölzhäuser, A. Turchanin, Nanoscale 2015, 7 (32), 13393. 
[33] W. Eck, V. Stadler, W. Geyer, M. Zharnikov, A. Gölzhäuser, M. Grunze, Adv. Mater. 2000, 12 (11), 805.

[34] A. Turchanin, M. Schnietz, M. El-Desawy, H. H. Solak, C. David, A. Gölzhauser, Small 2007, 3 (12), 2114.

[35] C. Neumann, R. A. Wilhelm, M. Küllmer, A. Turchanin, Faraday Discuss. 2021, 227 (0), 61.

[36] R. Dreos, S. Geremia, L. Randaccio, P. Siega, Properties, Structure and Reactivity of Cobaloximes. In PATAI'S Chemistry of Functional Groups, Wiley: Hoboken, NJ, 2010.

[37] E. Oswald, A. L. Gaus, J. Kund, M. Küllmer, J. Romer, S. Weizenegger, T. Ullrich, A. K. Mengele, L. Petermann, R. Leiter, P. R. Unwin, U. Kaiser, S. Rau, A. Kahnt, A. Turchanin, M. von Delius, C. Kranz, Chem. Eur. J. 2021.

[38] J. L. Dempsey, B. S. Brunschwig, J. R. Winkler, H. B. Gray, Acc. Chem. Res. 2009, 42 (12), 1995.

[39] V. Artero, M. Chavarot-Kerlidou, M. Fontecave, Angew. Chem. Int. Ed. Engl. 2011, 50 (32), 7238.

[40] J. Willkomm, E. Reisner, Bull. Japan Soc. Coord. Chem. 2018, 71, 18.

[41] D. Dolui, S. Khandelwal, P. Majumder, A. Dutta, Chem. Commun. 2020, 56 (59), 8166.

[42] Please note that, while we disclose here the first method for its isolation, the complex salt $\left[\mathrm{Co}(\mathrm{dmgH})_{2}(\mathrm{py})_{2}\right]^{+}\left[\mathrm{Co}(\mathrm{dmgH})_{2} \mathrm{Cl}_{2}\right]^{-}$has been reported previously as an undesired side product: W. C. Trogler, R. C. Stewart, L. A. Epps, L. G. Marzilli, Inorg. Chem. 1974, 13 (7), 1564.

[43] B. Giese, J. Hartung, B. M. Pérez, J. Hartung, Chlorobis(dimethylglyoximato)(pyridine)cobalt(III). In Encyclopedia of Reagents for Organic Synthesis, Wiley: Hoboken, NJ, 2008.

[44] F. Shao, R. Zenobi, Anal. Bioanal. Chem. 2019, 411 (1), 37.

[45] X. Wang, S.-C. Huang, T.-X. Huang, H.-S. Su, J.-H. Zhong, Z.-C. Zeng, M.-H. Li, B. Ren, Chem. Soc. Rev. 2017, 46 (13), 4020.

[46] M. Richard-Lacroix, Y. Zhang, Z. Dong, V. Deckert, Chem. Soc. Rev. 2017, 46 (13), 3922.

[47] A. Beyer, A. Godt, I. Amin, C. T. Nottbohm, C. Schmidt, J. Zhao, A. Gölzhäuser, Phys. Chem. Chem. Phys. 2008, 10 (48), 7233.

[48] A. Turchanin, D. Kafer, M. El-Desawy, C. Woll, G. Witte, A. Golzhauser, Langmuir 2009, 25 (13), 7342 .

[49] Y. Zubavichus, M. Zharnikov, Y. Yang, O. Fuchs, E. Umbach, C. Heske, A. Ulman, M. Grunze, Langmuir 2004, 20 (25), 11022.

[50] P. M. Dietrich, C. Streeck, S. Glamsch, C. Ehlert, A. Lippitz, A. Nutsch, N. Kulak, B. Beckhoff, W. E. S. Unger, Anal. Chem. 2015, 87 (19), 10117.

[51] N. M. Muresan, J. Willkomm, D. Mersch, Y. Vaynzof, E. Reisner, Angew. Chem. Int. Ed. Engl. 2012, 51 (51), 12749.

[52] A. M. Beiler, D. Khusnutdinova, S. I. Jacob, G. F. Moore, Ind. Eng. Chem. Res. 2016, 55 (18), 5306. 
[53] H. Kampmann. Über das Wachstum und die Struktur Selbstorganisierender Monolagen. Dissertation, University Bielefeld, 2014.

[54] T. Deckert-Gaudig, V. Deckert, Small 2009, 5 (4), 432.

[55] M. Richard-Lacroix, V. Deckert, Light Sci. Appl. 2020, 9, 35.

[56] T. Deckert-Gaudig, E. Kämmer, V. Deckert, J. Biophotonics 2012, 5 (3), 215.

[57] F. Latorre, S. Kupfer, T. Bocklitz, D. Kinzel, S. Trautmann, S. Grafe, V. Deckert, Nanoscale 2016, 8 (19), 10229.

[58] J. Lee, K. T. Crampton, N. Tallarida, V. A. Apkarian, Nature 2019, 568 (7750), 78.

[59] S. Trautmann, J. Aizpurua, I. Götz, A. Undisz, J. Dellith, H. Schneidewind, M. Rettenmayr, V. Deckert, Nanoscale 2017, 9 (1), 391.

[60] R. Zhang, Y. Zhang, Z. C. Dong, S. Jiang, C. Zhang, L. G. Chen, L. Zhang, Y. Liao, J. Aizpurua, Y. Luo, J. L. Yang, J. G. Hou, Nature 2013, 498 (7452), 82.

[61] X. Zhang, M. Mainka, F. Paneff, H. Hachmeister, A. Beyer, A. Gölzhäuser, T. Huser, Langmuir 2018, 34 (8), 2692.

[62] J. Ehrens, F. Gayk, P. Vorndamme, T. Heitmann, N. Biere, D. Anselmetti, X. Zhang, A. Gölzhäuser, J. Schnack, Phys. Rev. B 2021, 103 (11).

[63] S. Min Park, K. Kim, M. Soo Kim, J. Mol. Struct. 1994, 328, 169.

[64] L. K. Noda, O. Sala, J. Mol. Struct. 1987, 162 (1), 11.

[65] X. Ling, J. Wu, W. Xu, J. Zhang, Small 2012, 8 (9), 1365.

[66] L. Langelüddecke, P. Singh, V. Deckert, Appl. Spectrosc. 2015, 69 (12), 1357.

[67] P. Singh, T. Deckert-Gaudig, H. Schneidewind, K. Kirsch, E. M. van Schrojenstein Lantman, B. M. Weckhuysen, V. Deckert, Phys. Chem. Chem. Phys. 2015, 17 (5), 2991.

[68] S. Datta, A. S. Mahapatra, P. Sett, M. Ghosh, P. K. Mallick, P. K. Chakrabarti, Bull. Mater. Sci. 2018, $41(2), 60$.

[69] R. Böhme, M. Mkandawire, U. Krause-Buchholz, P. Rösch, G. Rödel, J. Popp, V. Deckert, Chem. Commun. 2011, 47 (41), 11453. 


\title{
Supporting Information
}

\section{Synthesis and nanoscale characterization of hierarchically assembled molecular nanosheets}

\author{
Marie Richard-Lacroix, ${ }^{1,2 \otimes *}$ Maria Küllmer, ${ }^{1 \otimes}$ Anna Laurine Gaus,${ }^{3}$ Christof Neumann, ${ }^{1}$ \\ Christian Tontsch, ${ }^{3}$ Max von Delius, ${ }^{3 *}$ Volker Deckert $1,2,4,6^{*}$, Andrey Turchanin ${ }^{1,5,6^{*}}$ \\ ${ }^{I}$ Institute of Physical Chemistry and Abbe Center of Photonics, Friedrich Schiller University \\ Jena, 07743 Jena, Germany \\ ${ }^{2}$ Leibniz Institute of Photonic Technology, 07745 Jena, Germany \\ ${ }^{3}$ Institute of Organic Chemistry, Ulm University, 89081 Ulm, Germany \\ ${ }^{4}$ Institute of Quantum Science and Engineering, Texas A\&M University, \\ College Station, TX 77843, USA \\ ${ }^{5}$ Center for Energy and Environmental Chemistry Jena (CEEC Jena), 07743 Jena, Germany \\ ${ }^{6}$ Jena Center for Soft Matter (JCSM), 07743 Jena, Germany
}

${ }^{\otimes}$ These authors contributed equally to this work

*Corresponding authors:

marie.richard-lacroix@uni-jena.de

max.vondelius@uni-ulm.de

volker.deckert@uni-jena.de

andrey.turchanin@uni-jena.de 


\section{Table of contents}

Section S1 - Experimental Section.

S1.1 - Synthesis 3

S.1.1.1 $\left[\mathrm{Co}(\mathrm{dmgH})_{2}(\mathrm{py})_{2}\right]^{+}\left[\mathrm{Co}(\mathrm{dmgH})_{2} \mathrm{Cl}_{2}\right]^{-} \quad 3$

S.1.1.2 $\mathrm{NH}_{2}$-CNM: NBPT self-assembled monolayers and carbon nanomembrane $\begin{array}{ll}\text { preparation } & 6\end{array}$

S.1.1.3 - Iso-CNM: Isonicotinic acid functionalization of the CNM membrane 7

S.1.1.4 - Co(III)-CNM: Immobilization of $\mathrm{Co}^{+} \mathrm{Co}^{-}$double complex salt on iso-CNM 8

S.1.1.5 - Transfer of the CNMs on TERS compatible substrates 8

$\begin{array}{ll}\text { S.1.2. Membrane characterization. } & 9\end{array}$

$\begin{array}{ll}\text { S.1.2.1 - XPS characterization } & 9\end{array}$

$\begin{array}{ll}\text { S.1.2.2 - TERS experiments } & 9\end{array}$

Section S2. XPS Quantification. 11

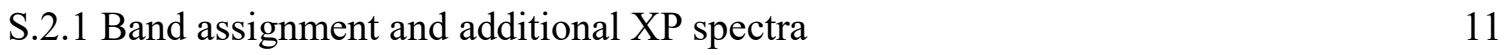

S.2.2. Estimation of the Co $2 \mathrm{p} \mathrm{XP} \mathrm{signal} \mathrm{intensity} \mathrm{in} \mathrm{the} \mathrm{case} \mathrm{of} \mathrm{low} \mathrm{Co}^{+} \mathrm{Co}^{-}$complex surface number density 13

S.2.3. Estimation of Co-complex surface number density from N 1s XPS signal 17

Section S5. Raman spectroscopy investigation of the $\mathrm{Co}^{+} \mathrm{Co}^{-}$double salt complex. $\quad 25$

Section S6. TERS investigation of the $\mathrm{Co}^{+} \mathrm{Co}^{-}$double salt complex immobilization. $\quad 26$ 


\section{Section S1 - Experimental Section.}

\section{S1.1 - Synthesis}

All chemicals were used as purchased unless otherwise mentioned $\left(\left[\mathrm{Co}(\mathrm{dmgH})_{2}(\mathrm{py}) \mathrm{Cl}\right]\right.$ from Sigma-Aldrich; tris(pentafluorophenyl)borane from ABCR). Solvent acetonitrile was dried on an MBraun solvent purification system (SPS). NMR spectra were recorded on a Bruker Avance (Neo) 400 spectrometer. Mass spectrometry was performed on an Agilent QTOF 6546 mass spectrometer (direct infusion).

\section{S.1.1.1 $\left[\mathrm{Co}(\mathrm{dmgH})_{2}(\mathrm{py})_{2}\right]^{+}\left[\mathrm{Co}(\mathrm{dmgH})_{2} \mathrm{Cl}_{2}\right]^{-}$}

$\left[\mathrm{Co}(\mathrm{dmgH})_{2}(\mathrm{py})_{2}\right]^{+}\left[\mathrm{Co}\left(\mathrm{dmgH}_{2}\right) \mathrm{Cl}_{2}\right]^{-}\left(\mathrm{Co}^{+} \mathrm{Co}^{-}\right.$double complex salt $)$was prepared by stirring $\left[\mathrm{Co}(\mathrm{dmgH})_{2}(\mathrm{py}) \mathrm{Cl}\right](52 \mathrm{mg}, 0.124 \mathrm{mmol})$ at room temperature with tris(pentafluorophenyl)borane (6.9 mg, $0.012 \mathrm{mmol}, 0.1$ eq.) in anhydrous acetonitrile $(2.5 \mathrm{~mL})$ under argon for $4.5 \mathrm{~h}$. The resulting precipitate was collected and washed with diethyl ether $(1.0 \mathrm{~mL})$, ethanol $(1.0 \mathrm{~mL})$, and $\mathrm{H}_{2} \mathrm{O} \quad(1.0 \mathrm{~mL})$, to yield pure $\left[\mathrm{Co}(\mathrm{dmgH})_{2}(\mathrm{py})_{2}\right]^{+}\left[\mathrm{Co}(\mathrm{dmgH})_{2} \mathrm{Cl}_{2}\right]^{-}$as a brown solid $(20 \mathrm{mg}$, $40 \%$ ) after drying under reduced pressure.

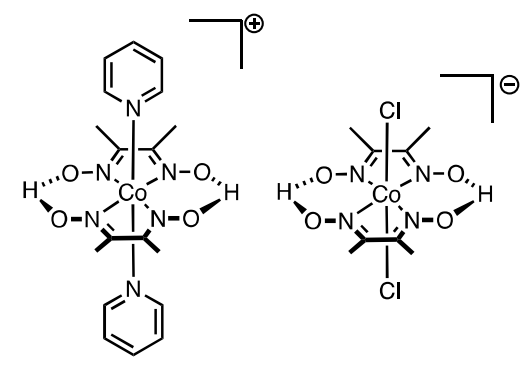

${ }^{1} \mathrm{H}-\mathrm{NMR}\left(400 \mathrm{MHz}\right.$, acetonitrile- $\left.d_{3}\right): \delta=8.24-8.23\left(\mathrm{dd}, J_{l}=6.9 \mathrm{~Hz}, J_{2}=1.3 \mathrm{~Hz}, 4 \mathrm{H}, \mathrm{CH}_{\mathrm{py}}\right.$ ), 7.89 - 7.85 (m, 2H, $\left.\mathrm{CH}_{\mathrm{py}}\right), 7.41$ - $7.38\left(\mathrm{~m}, 4 \mathrm{H}, \mathrm{CH}_{\mathrm{py}}\right), 2.39$ (s, 12H, $\left.\mathrm{CH}_{3}\right), 2.24\left(\mathrm{~s}, 12 \mathrm{H}, \mathrm{CH}_{3}\right) \mathrm{ppm}$.

${ }^{13} \mathrm{C}-U D E F T-N M R\left(100 \mathrm{MHz}, 298 \mathrm{~K}, \mathrm{DMF}-d_{7}\right): \delta=157.9,152.1,150.1,141.6,127.9,13.8,12.7$ ppm.

HR MS (ESI): positive mode: Calculated for $\mathrm{C}_{18} \mathrm{H}_{24} \mathrm{CoN}_{6} \mathrm{O}_{4}: 447.1186$. Found: $447.1186 \mathrm{~m} / \mathrm{z}$. negative mode: Calculated for $\mathrm{C}_{8} \mathrm{H}_{14} \mathrm{Cl}_{2} \mathrm{CoN}_{4} \mathrm{O}_{4}$ : 358.9730 . Found: $358.9736 \mathrm{~m} / \mathrm{z}$. 


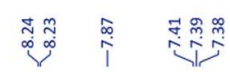
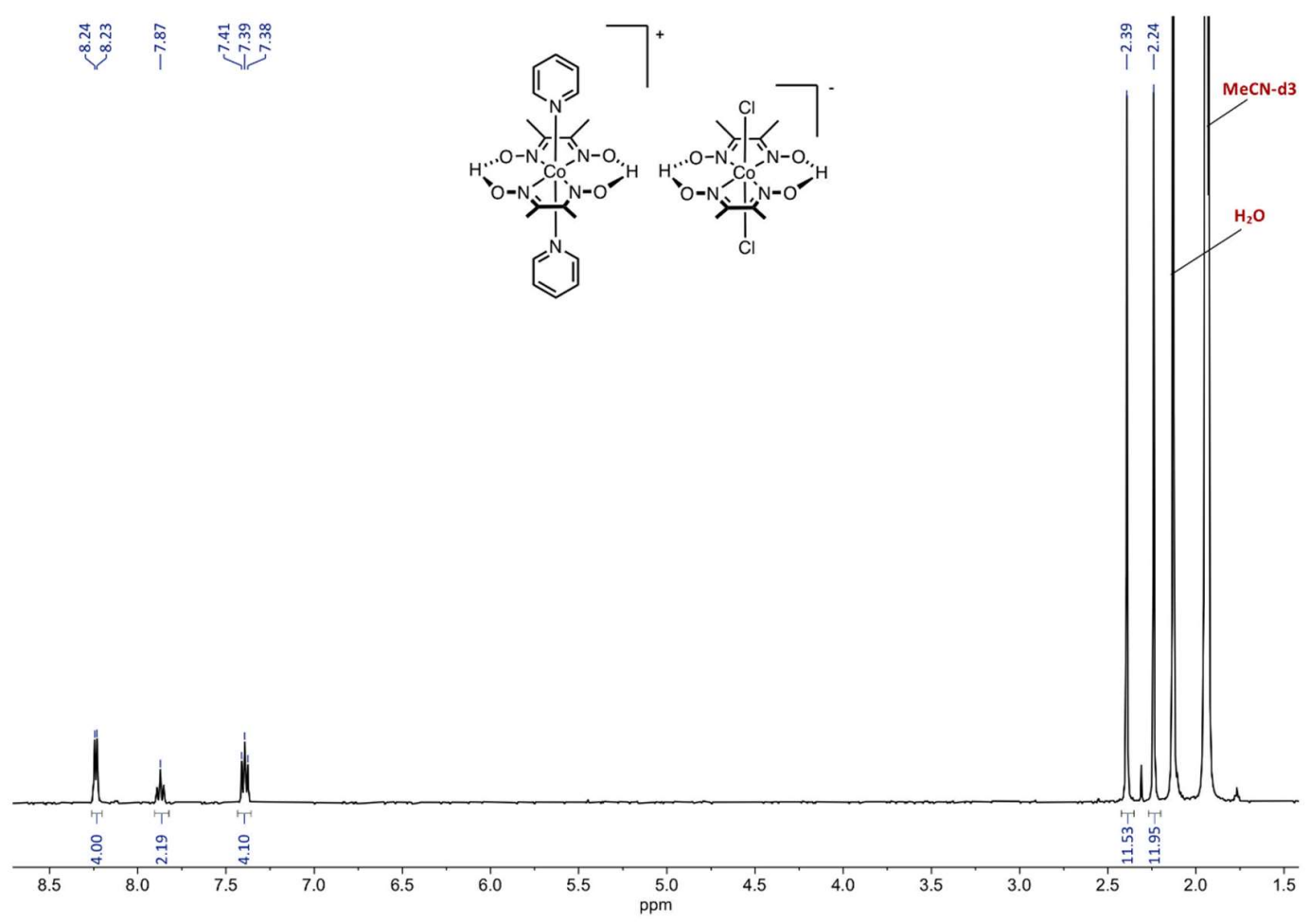

Figure S1: ${ }^{1} \mathrm{H}-\mathrm{NMR}$ spectrum $\left(400 \mathrm{MHz}, \mathrm{CD}_{3} \mathrm{CN}, 295 \mathrm{~K}\right)$ of $\left[\mathrm{Co}(\mathrm{dmgH})_{2}(\mathrm{py})_{2}\right]^{+}\left[\mathrm{Co}(\mathrm{dmgH})_{2} \mathrm{Cl}_{2}\right]^{-}$

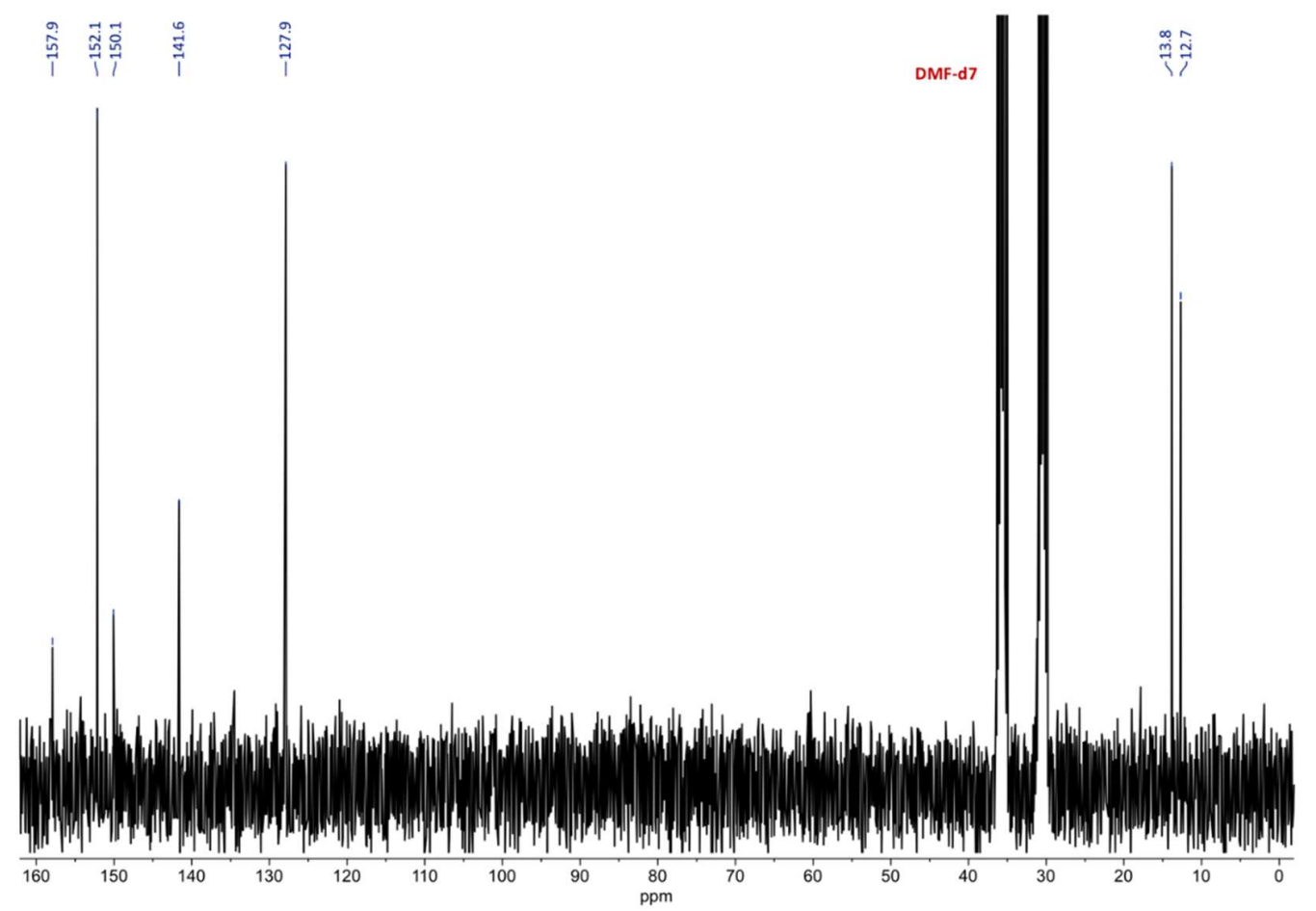

Figure S2: $\quad{ }^{13} \mathrm{C}-\mathrm{UDEFT}-\mathrm{NMR} \quad$ spectrum $\quad(100 \mathrm{MHz}, \quad$ IMF- $d 7, \quad 295 \quad \mathrm{~K}) \quad$ of $\left[\mathrm{Co}(\mathrm{dmgH})_{2}(\mathrm{py})_{2}\right]^{+}\left[\mathrm{Co}(\mathrm{dmgH})_{2} \mathrm{Cl}_{2}\right]^{\text {. }}$.

S 4 

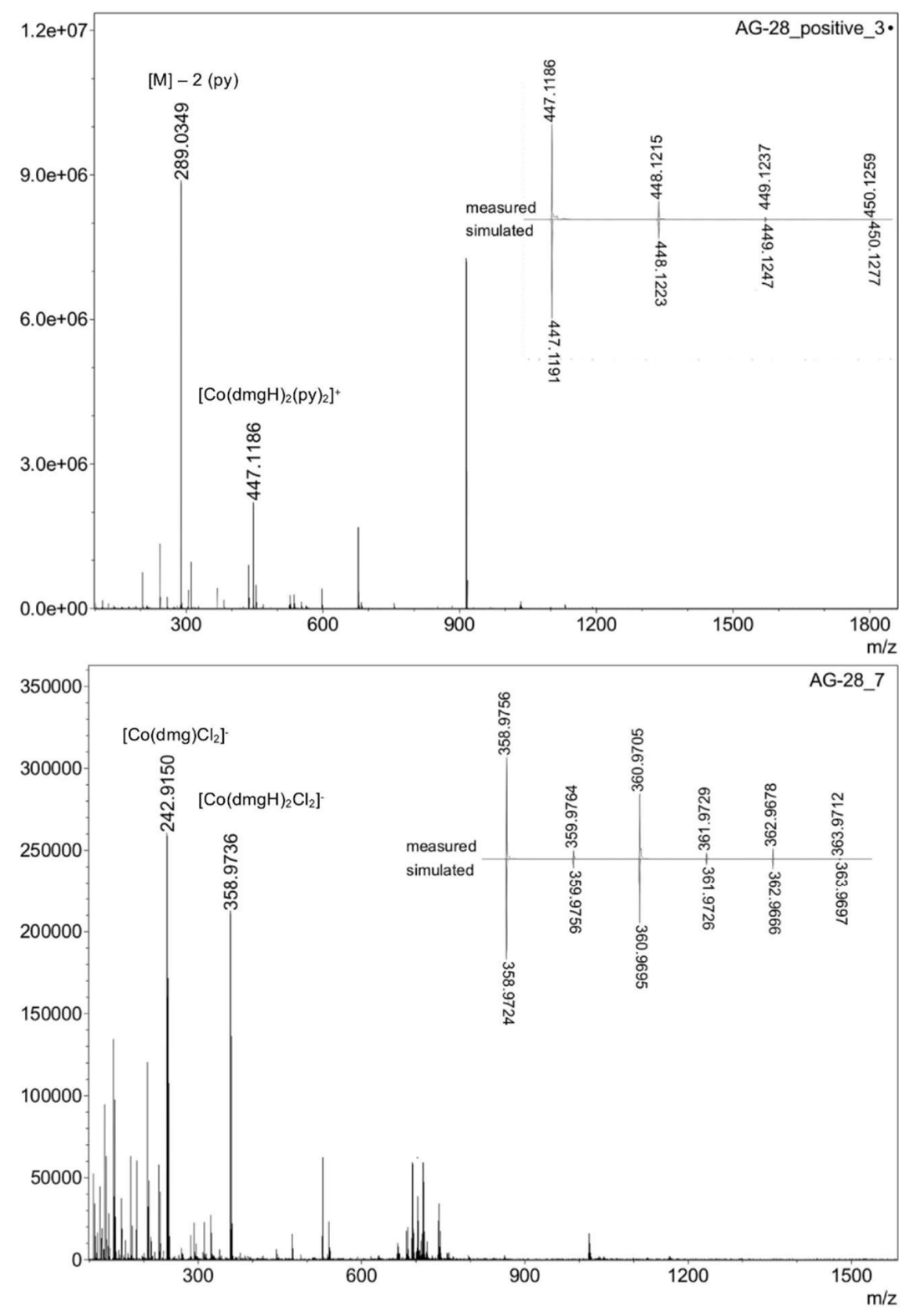

Figure S3. Top: HR MS (ESI) positive mode of $\left[\mathrm{Co}(\mathrm{dmgH})_{2}(\mathrm{py})_{2}\right]^{+}\left[\mathrm{Co}(\mathrm{dmgH})_{2} \mathrm{Cl}_{2}\right]^{-}$calculated for $\mathrm{C}_{18} \mathrm{H}_{24} \mathrm{CoN}_{6} \mathrm{O}_{4}: 447.1186$. Found: $447.1286 \mathrm{~m} / \mathrm{z} . \mathrm{m} / \mathrm{z}: 289.0349$ corresponds to $\left[\mathrm{Co}(\mathrm{dmgH})_{2}\right]^{+}$. Bottom: HR MS (ESI) negative mode of $\left[\mathrm{Co}(\mathrm{dmgH})_{2}(\mathrm{py})_{2}\right]^{+}\left[\mathrm{Co}(\mathrm{dmgH})_{2} \mathrm{Cl}_{2}\right]^{-}$calculated for $\mathrm{C}_{8} \mathrm{H}_{14} \mathrm{Cl}_{2} \mathrm{CoN}_{4} \mathrm{O}_{4}$ : 358.9730. Found: $358.9736 \mathrm{~m} / \mathrm{z}$. m/z: 242.9150 corresponds to $\mathrm{C}_{4} \mathrm{H}_{6} \mathrm{Cl}_{2} \mathrm{CoN}_{2} \mathrm{O}_{2}$. 


\section{S.1.1.2 $\mathrm{NH}_{2}$-CNM: NBPT self-assembled monolayers and carbon nanomembrane preparation}

Self-assembled monolayers (SAMs) were produced under nitrogen atmosphere by immersion of the oxygen plasma cleaned, $300 \mathrm{~nm}$ thick gold layer, thermally evaporated on flat Mica substrates (Georg Albert PVD coatings) in a $0.2 \mathrm{mmol} / 1$ solution of $4,4^{\prime}$-nitrobiphenylthiol (NBPT) (99\%, Taros, sublimated before use) in N,N-dimethylformamide (DMF, 99.8\% anhydrous, Alfa Aesar) for $72 \mathrm{~h}$. Detailed information of the production of carbon nanomembrane from the SAM can be found elsewhere while the general process is schematically presented in Figure S4. ${ }^{[1,2]}$ Briefly, after subsequent rinsing with DMF and ethanol (HPLC grade, VWR) and blow-drying $\left(\mathrm{N}_{2}\right)$, the SAMs were crosslinked into a carbon nanomembrane by low-energy electron irradiation (electron energy of $100 \mathrm{eV}$ with a dose of $50 \mathrm{mC} / \mathrm{cm}^{2}$ ) under high vacuum conditions with a flood gun (FG15/40 Specs, $1 \times 10^{-8}$ mbar).

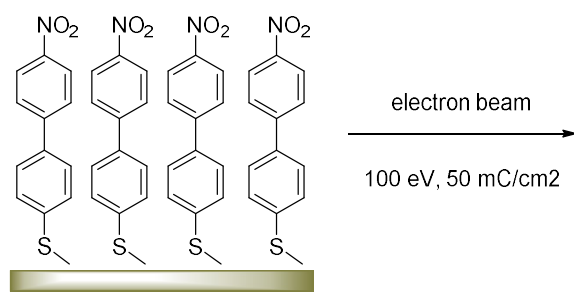

NBPT SAM

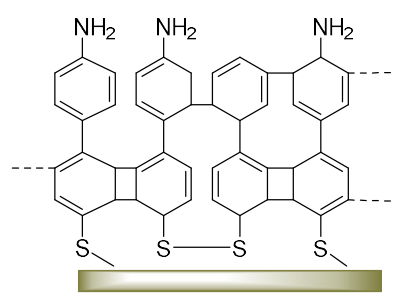

$\mathrm{NH}_{2}-\mathrm{CNM}$

Figure S4. Schematic representation of the $\mathrm{NH}_{2}-\mathrm{CNM}$ production by low-energy electron irradiation of an NBPT SAM. 


\section{S.1.1.3 - Iso-CNM: Isonicotinic acid functionalization of the CNM membrane}

$0.13 \mathrm{mmol}$ of isonicotinic acid (Alfa Aesar) was dissolved in $15 \mathrm{ml}$ DMF (peptide synthesis grade, Carl Roth) and $20.4 \mu 1 \mathrm{~N}, N$-diisopropylethylamine (DIPEA) (peptide synthesis grade, Carl Roth). The solution was then cooled in an ice bath, degassed with Argon and a second solution of $0.13 \mathrm{mmol}$ of 1-[(1-(cyano-2-ethoxy-2-oxoethylideneaminooxy)dimethylamino-morpholino)]uronium hexafluorophosphate (COMU) (Carl Roth) dissolved in $1.5 \mathrm{ml}$ of DMF was added slowly. After stirring for 10 min under argon atmosphere, the freshly prepared $\mathrm{NH}_{2}-\mathrm{CNM}$ was immersed into the solution where an additional $20.4 \mu 1$ of DIPEA was added. The substrates in solution were heated at $70{ }^{\circ} \mathrm{C}$ for $4 \mathrm{~h}$ under argon atmosphere to create the surface shown in Figure S5. After cooling to room temperature, the substrate was rinsed successively with DMF, dichloromethane (DCM, HPLC grade, VWR) and ethanol (HPLC grade, VWR) and lastly dried under continuous nitrogen flow.

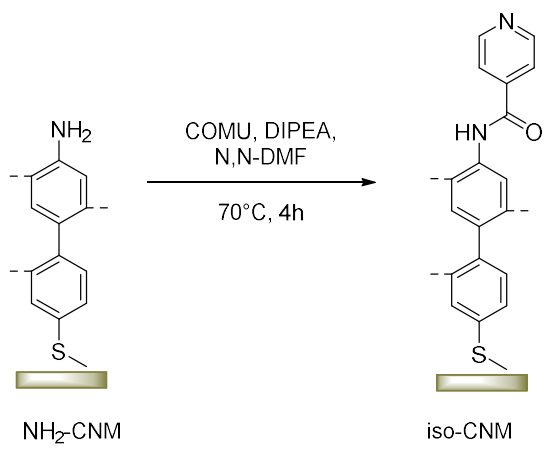

Figure S5. Schematic representation of the functionalization of the $\mathrm{NH}_{2}-\mathrm{CNM}$ nanosheet with isonicotinic acid by amide bond formation. 


\section{S.1.1.4 - Co(III)-CNM: Immobilization of $\mathrm{Co}^{+} \mathrm{Co}^{-}$double complex salt on iso-CNM}

$0.7 \mathrm{mg}$ of the $\mathrm{Co}^{+} \mathrm{Co}^{-}$double complex salt was dissolved in $2 \mathrm{ml}$ of DMF (peptide synthesis, Carl Roth). The freshly prepared iso-CNM was immersed in this solution for $24 \mathrm{~h}$ in the dark for cobalt complex immobilization (see Figure S6). Afterwards the substrate was thoroughly rinsed with DMF (HPLC grade, VWR) and ethanol (HPLC grade, VWR) and dried under a stream of nitrogen.

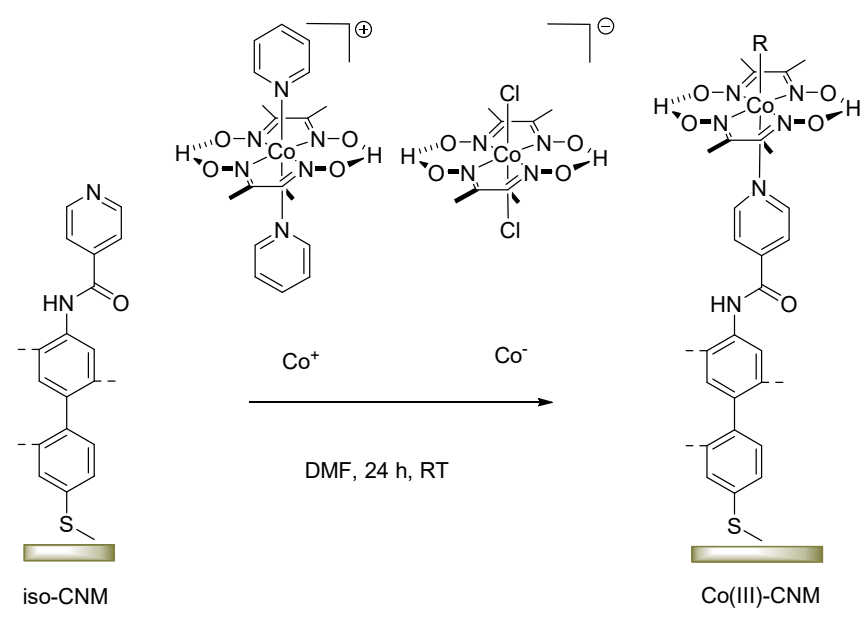

Figure S6. Schematic representation of the Co(III)-CNM membrane, where the pyridine group of iso-CNM act as a ligand for cobalt double salt complex immobilization.

\section{S.1.1.5 - Transfer of the CNMs on TERS compatible substrates}

After the characterization with XPS the CNMs were transferred on ultra-thin gold substrates (that are more convenient for TERS investigation) according to a poly(methylmethacrylat) (PMMA) assisted transfer procedure described elsewhere. ${ }^{[3]}$ Briefly two layers of two different ebeam resists (AR-P 631.04 and AR-P 671.04, Allresist) were successively spin-coated at $4000 \mathrm{rpm}$ for $1 \mathrm{~min}$ and cured at $60{ }^{\circ} \mathrm{C}$ on a hotplate. Then; the PMMA/CNM/Au film was mechanically detached from the mica support on a water bath to obtain a free-floating multilayered sample. The gold layer was etched on an aqueous iodine /potassium iodide solution (mass ratio $\mathrm{I}_{2} / \mathrm{KI} / \mathrm{H}_{2} \mathrm{O}$ 1:4:10, Sigma Aldrich, Carl Roth). After transfer on an aqueous sodium thiosulfate solution (40 $\mathrm{mmol} / \mathrm{l}$, Carl Roth) and several times rinsing on ultrapure water, the membrane coated with the polymer layer was transferred to the ultra-thin gold substrate and dried $60 \mathrm{~min}$ at $60{ }^{\circ} \mathrm{C}$ on a 
hotplate. The PMMA layer was removed in an overnight acetone bath (HPLC grade, VWR). The sample was finally rinsed with acetone, isopropanol (HPLC grade, VWR) and dried under a stream of nitrogen.

\section{S.1.2. Membrane characterization.}

\section{S.1.2.1 - XPS characterization}

XPS characterization was carried out in an UHV Multiprobe system (Scienta Omicron) with a base pressure of $2 \times 10^{-10}$ mbar. The samples were irradiated with a monochromatic $\mathrm{Al} \mathrm{K} \mathrm{K}_{\alpha} \mathrm{X}$-ray source and analyzed with an electron analyser (Argus CU) with a spectral resolution of $0.6 \mathrm{eV}$ under an emission angle of $18.7^{\circ}$. For angle dependant XP spectroscopy, the emission angle was varied between $60^{\circ}$ and $80^{\circ}$. The spectra were fitted with CasaXPS applying Voigt functions after background subtraction using a Shirley (C 1s, Au 4f, Co 2p reference) or linear background (N 1s, $\mathrm{Cl} 2 \mathrm{p}, \mathrm{F} 1 \mathrm{~s}, \mathrm{~S} 2 \mathrm{p}$ ). Background correction in the spectral region of Co $2 \mathrm{p}$ was done for CNM samples by averaging eight spectra measured from samples without Co(III) complex after normalization. All XP spectra were calibrated to the $A u 4 f_{7 / 2}$ signal at $84.0 \mathrm{eV}$. The effective thicknesses, $d$, of the CNMs and the drop casted reference sample $\left(\mathrm{Co}^{+} \mathrm{Co}^{-}\right.$in acetonitrile) were calculated by Beer-Lambert law comparing the attenuation of the $A u 4 f_{7 / 2}$ intensities to an atomically clean gold reference (inelastic mean free path $\lambda$ of $36 \AA$ ) for several samples. Thicknesses were found to be in average $d\left(\mathrm{NH}_{2}-\mathrm{CNM}\right)=1.1 \mathrm{~nm}, d$ (iso-CNM) $=1.3 \mathrm{~nm}$ and $d(\mathrm{Co}(\mathrm{III})-\mathrm{CNM})=1.3 \mathrm{~nm}$. The effective thickness of the reference sample was calculated to be $4.8 \mathrm{~nm}$. Thickness differences between $\mathrm{NH}_{2}-\mathrm{CNM}$ and the functionalized CNMs as well as comparison of the $\mathrm{N} 1 \mathrm{~s}$ components areas enabled quantification of the XPS data as described in Section 2.

\section{S.1.2.2 - TERS experiments}

The TERS setup and the detailed procedure for TERS experiments were described in Ref. ${ }^{[4]}$ In summary, the system used a $532 \mathrm{~nm}$ laser excitation (Cobolt 04-01 series, Hubner Photonics, Germany) with a power of $100 \mu \mathrm{W}$, unless stated otherwise in the main text, at the sample to avoid any burning. It is composed of a Raman spectrometer (SP300, Teledyne Princeton Instruments, USA) equipped with a CCD camera (PIXIS400, Teledyne Princeton Instruments, USA), coupled to an AFM head (NanoWizard 2, Bruker-JPK, Germany) via an inverted microscope equipped 
with a $100 \mathrm{X}$ oil immersion objective (NA 1.30, Olympus, Japan) for sample and tip illumination. Ag coated silicon AFM tips (Tap 190-Al-G, Budget Sensors) are first positioned in the focus of the laser spot by optimizing the intensity of the silicon signal using the tip scanner. Sample scanning is then used to preserve the tip/laser focus positioning while controlling the sample position during the experiments. A full set of $532 \mathrm{~nm}$ volume Bragg notch filters (OptiGrate, USA) was used to reject the laser line. AFM images were acquired using the same tip, prior to spectral acquisition. Typically, $400 \times 400 \mathrm{~nm}^{2}$ areas were scanned and a TERS grid with $25 \mathrm{~nm}$ distance between points was set. The tip was then placed at subsequently at those points for the TERS experiments. Acquisition time for each TERS spectrum was 3 seconds and the average of 3 acquisitions at each of the point of the map was used. All results presented have been reproduced at least once with two different tips. In the context of the $\mathrm{NH}_{2}-\mathrm{CNM}$ membrane investigation, no consistent TERS signal has been observed with use of 8 different, freshly prepared TERS tips. 


\section{Section S2. XPS Quantification.}

\section{S.2.1 Band assignment and additional XP spectra}

Table S1. Analysis and peak assignment of the XP spectra presented in Figure 2. The deconvolution of the high-resolution $\mathrm{XP}$ spectra of $\mathrm{NH}_{2}-\mathrm{CNM}$, iso-CNM, $\mathrm{Co}$ (III)-CNM and reference sample are shown with peak position, full width at half maximum (FWHM) and relative component area. Assignments were prepared in accordance to the literature or the reference sample as indicated in the table.

\begin{tabular}{|c|c|c|c|c|}
\hline Sample & Peak assignment & Position, eV & FWHM, eV & Area, $\%$ \\
\hline \multicolumn{5}{|c|}{$\mathrm{C} 1 \mathrm{~s}$} \\
\hline \multirow[t]{4}{*}{$\mathrm{NH}_{2}-\mathrm{CNM}^{[2,5]}$} & $\mathrm{C}-\mathrm{C}$ & 284.1 & 1.2 & 63 \\
\hline & C-S, C-N & 285.0 & 1.4 & 20 \\
\hline & Satellite & 286.4 & 1.9 & 11 \\
\hline & Satellite & 288.6 & 3.2 & 6 \\
\hline \multirow[t]{4}{*}{ Iso-CNM } & C-C, pyridine ${ }^{[6]}$ & 284.3 & 1.2 & 64 \\
\hline & C-S, C-N, pyridine ${ }^{[6]}$ & 285.3 & 1.6 & 19 \\
\hline & Satellite & 286.7 & 2.0 & 9 \\
\hline & Satellite, $-\mathrm{C}(=\mathrm{O}) \mathrm{NH}_{-}{ }^{[7]}$ & 288.6 & 3.0 & 8 \\
\hline \multirow[t]{4}{*}{ Co(III)-CNM } & C-C, pyridine & 284.2 & 1.2 & 63 \\
\hline & C-S, C-N, pyridine ${ }^{[8]}$ & 285.3 & 1.7 & 22 \\
\hline & Satellite, $-\mathrm{C}=\mathrm{N}-\mathrm{O}-$ & 287.0 & 2.1 & 11 \\
\hline & Satellite, $-\mathrm{C}(=\mathrm{O}) \mathrm{NH}-$ & 289.1 & 2.5 & 3 \\
\hline \multirow[t]{3}{*}{ Reference } & C-C, pyridine & 285.5 & 1.9 & 79 \\
\hline & $-\mathrm{C}=\mathrm{N}-\mathrm{O}-$ & 287.1 & 2.0 & 17 \\
\hline & Satellite & 292.4 & 2.3 & 4 \\
\hline \multicolumn{5}{|c|}{ Co $2 p_{3 / 2}$, Co $2 p_{1 / 2}$} \\
\hline Reference & $\mathrm{Co}(\mathrm{III})$ ions $^{[8]}$ & $781.5,796.5$ & $2.0,2.0$ & \\
\hline \multicolumn{5}{|c|}{$\mathrm{N} 1 \mathrm{~s}$} \\
\hline $\mathrm{NH}_{2}-\mathrm{CNM}$ & Amino group ${ }^{[2,5]}$ & 398.9 & 2.3 & 100 \\
\hline \multirow[t]{2}{*}{ Iso-CNM } & Amino group & 399.0 & 2.1 & 45 \\
\hline & $\begin{array}{l}\text { Amide, }{ }^{[7]} \text { pyridine associated with } \\
\text { protons }{ }^{[6]}\end{array}$ & 399.8 & 2.1 & 55 \\
\hline \multirow[t]{3}{*}{ Co(III)-CNM } & Amino group & 399.0 & 2.2 & 48 \\
\hline & Amide, pyridine & 399.8 & 2.1 & 35 \\
\hline & $\begin{array}{l}\mathrm{Co}^{+} \mathrm{Co}^{-} \text {oxime ligands, bound } \\
\text { isonicotinic acid }{ }^{[8,9]}\end{array}$ & 400.9 & 2.3 & 17 \\
\hline \multirow[t]{2}{*}{ Reference } & $\mathrm{Co}^{+} \mathrm{Co}^{-}$oxime ligands & 400.8 & 1.6 & 86 \\
\hline & & 404.1 & 3.0 & 14 \\
\hline \multicolumn{5}{|c|}{$\mathrm{Cl} 2 \mathrm{p}_{3 / 2}, \mathrm{Cl} 2 \mathrm{p}_{1 / 2}$} \\
\hline Reference & Chloride ligand $^{[10]}$ & $198.4,200.0$ & $1.2,1.2$ & \\
\hline \multicolumn{5}{|c|}{$\mathrm{S} 2 \mathrm{p}_{3 / 2}, \mathrm{~S} 2 \mathrm{p}_{1 / 2}$} \\
\hline \multirow[t]{2}{*}{$\mathrm{NH}_{2}-\mathrm{CNM}$} & $\mathrm{R}-\mathrm{S}-\mathrm{Au}^{[11,12]}$ & $161.9,163.1$ & 1.3 & 52 \\
\hline & R-S-S-R, R-SH ${ }^{[1,12]}$ & $163.3,164.5$ & 1.3 & 48 \\
\hline \multirow[t]{2}{*}{ Iso-CNM } & $\mathrm{R}-\mathrm{S}-\mathrm{Au}$ & $161.9,163.1$ & 1.3 & 51 \\
\hline & R-S-S-R, R-SH & $163.4,164.6$ & 1.1 & 49 \\
\hline \multirow[t]{2}{*}{$\mathrm{Co}(\mathrm{III})-\mathrm{CNM}$} & R-S-Au & $161.9,163.1$ & 1.3 & 55 \\
\hline & R-S-S-R, R-SH & $163.3,164.5$ & 1.0 & 45 \\
\hline
\end{tabular}




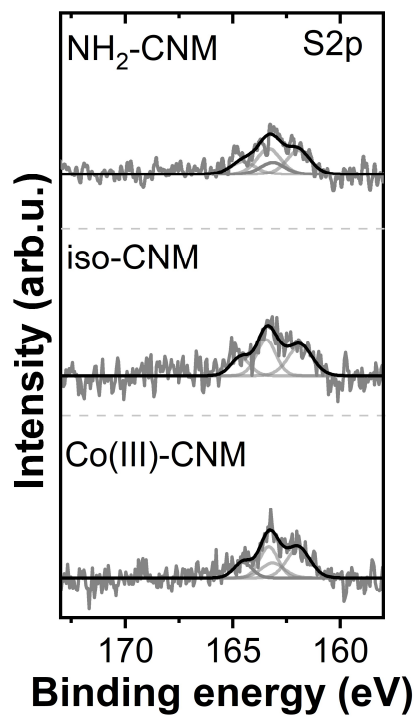

Figure S7. XP spectra of the $\mathrm{S} 2 \mathrm{p}$ binding energy range of the $\mathrm{NH}_{2}-\mathrm{CNM}$, iso-CNM and $\mathrm{Co}$ (III)CNM. All CNM types show the presence of thiolates $(161.9 \mathrm{eV}, 163.1)$ and disulfides or unbound thiols $(163.3 \mathrm{eV}, 164.5 \mathrm{eV})$.

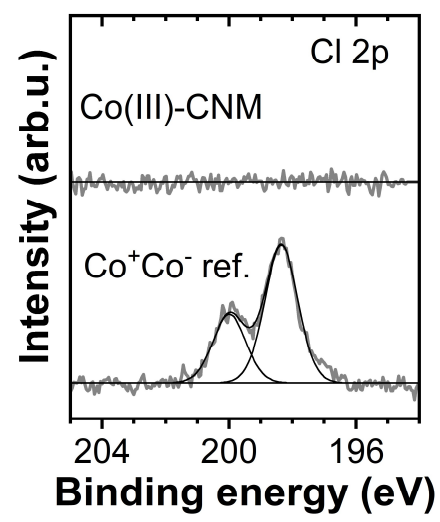

Figure S8. XP spectra of the $\mathrm{Cl} 2 \mathrm{p}$ binding energy range of the $\mathrm{Co}(\mathrm{III})-\mathrm{CNM}$ and the reference sample. No chloride peak could be found for the Co(III)-CNM in the $\mathrm{Cl} 2 \mathrm{p}$ spectral range. In the reference sample, the $\mathrm{Cl} 2 \mathrm{p}$ doublet at $198.4 \mathrm{eV}$ and $200.0 \mathrm{eV}$ is assigned to the chloride ligands in the $\mathrm{Co}^{+} \mathrm{Co}^{-}$double salt. 


\section{S.2.2. Estimation of the Co 2p XP signal intensity in the case of low $\mathrm{Co}^{+} \mathrm{Co}^{-}$complex}

surface number density

As no quantifiable Co 2p XP signal was observed in the high-resolution spectra of Co(III)$\mathrm{CNM}$, we estimated the lowest surface number density of the $\mathrm{Co}^{+} \mathrm{Co}^{-}$-complex which can still be detected within our instrument XPS setup. To this end, we considered the hypothetical model of a 1:1 immobilization of $\mathrm{Co}^{+}$and $\mathrm{Co}^{-}$on the iso-CNM surface as presented in Figure S9 b-c. The 3D structures of the complexes were adopted from crystal structures ${ }^{[13,14]}$ and evaluated with ArgusLab 4.0.1 for basic area and height calculations.
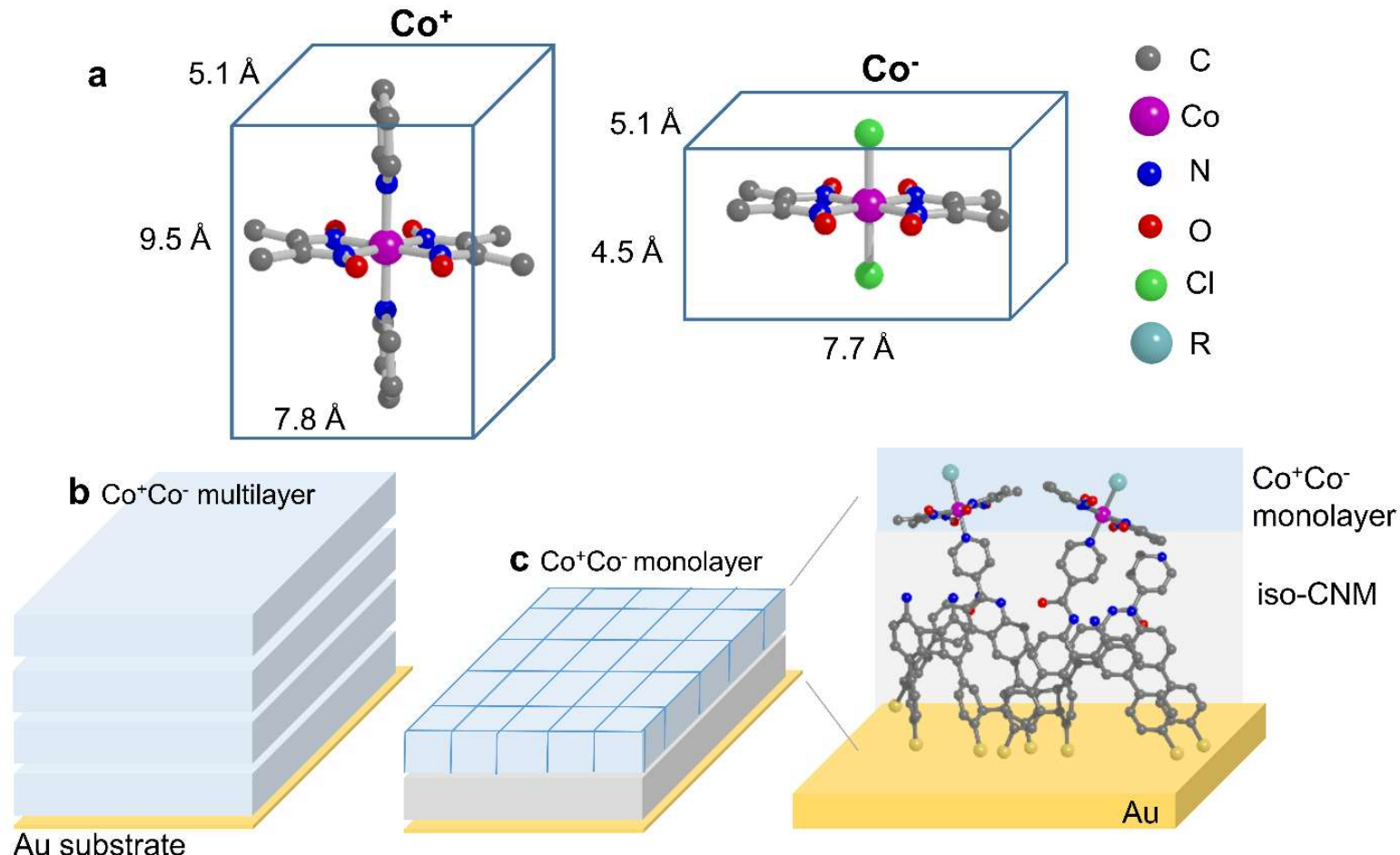

Figure S9. a) The approximate height and therefore area of both cobalt complexes $\left(\mathrm{Co}^{+}\right.$and $\left.\mathrm{Co}^{-}\right)$ can be estimated from their $3 \mathrm{D}$ representation using the distance between the outermost atoms. $\mathbf{b}$ ) The reference signal is taken from the measurement of a drop casted solution of $\mathrm{Co}^{+} \mathrm{Co}^{-}$on a gold surface (that typically creates a multilayer sample). c) The complex is assumed to form an upright standing monolayer of $\mathrm{Co}^{+}$and $\mathrm{Co}^{-}$on top of the iso-CNM.

XPS is a surface sensitive technique and the attenuation of the XP signals intensity $I$ can be quantified according to the Beer-Lambert law ${ }^{[15]}$ as 


$$
I_{1}=I_{0}\left(1-e^{-\frac{d_{C o}}{\lambda_{C o} \cos \theta}}\right)
$$

In our case, $\lambda_{\mathrm{Co}}$ is the inelastic mean free path of an Co $2 \mathrm{p}_{3 / 2}$ electron through a carbon layer $\left(\lambda_{\mathrm{Co}}=21 \AA\right) .{ }^{[16]} I_{0}$ is the signal of an infinitely thick sample, $d_{C o}$ is the thickness of the $\mathrm{Co}^{+} \mathrm{Co}^{-}$ layer and $\theta$ is the emission angle between the sample normal and the photoelectron detector $\left(\theta=18.7^{\circ}\right)$. The $\mathrm{Co}^{+} \mathrm{Co}^{-}$multilayer reference, Figure S9b and Figure 2, has an effective thickness $d_{C o}$ of $4.8 \mathrm{~nm}$ calculated by the attenuation of the $\mathrm{Au} 4 \mathrm{f}_{7 / 2}$ signal compared to a clean gold reference The height, and therefore the thickness $d_{C o}$ of a $\mathrm{Co}^{+} \mathrm{Co}^{-}$-complex monolayer can be estimated considering its 3D structure, Figure S9a. Assuming an upright orientation with respect to the surface and a 1:1 immobilization of $\mathrm{Co}(\mathrm{III})$ anion and cation, the average height of a $\mathrm{Co}^{+} \mathrm{Co}^{-}$ monolayer is estimated to $\mathrm{d}_{\mathrm{Co}}=7 \AA$ (see Figure S9c).

Therefore, from Equation S1, the intensity of the Co 2p signal for a densely packed monolayer $\mathrm{Co}^{+} \mathrm{Co}^{-}$-monolayer, $I_{l}$, can be estimated, which equals to $32 \%$ of the multilayer references $I_{l}$ in Figure 2. This signal is further attenuated by the presense of an additional overlayer. As seen in Figure S9a, the Co atoms are placed in the center of the $\mathrm{Co}^{+} \mathrm{Co}^{-}$monolayer, i.e. under a layer of pyridine groups or $\mathrm{Cl}^{-}$atoms with the thickness equal to half of a monolayer. One can quantify the final intensity, $I_{2}$, using the following Beer-Lambert type equation. ${ }^{[15]}$

$$
I_{2}=I_{1}\left(e^{-\frac{d_{C o}}{2 \lambda \operatorname{co} \cos \theta}}\right)
$$

Therewith, $I_{2}$, is estimated to be $27 \%$ of the $\mathrm{Co}^{+} \mathrm{Co}^{-}$multilayers $I_{1}$. Based on these considerations, Figure S10 shows in grey the calculated intensity of the Co $2 p_{3 / 2,1 / 2}$ signals for a densely packed monolayer of the $\mathrm{Co}^{+} \mathrm{Co}^{-}$-complex superimposed with the experimentally measured spectrum of the $\mathrm{Co}^{+} \mathrm{Co}^{-}$reference. Here, the Co $2 \mathrm{p}$ reference signal fit was scaled respectively to $27 \%$ for representation of the calculated monolayer intensity. 


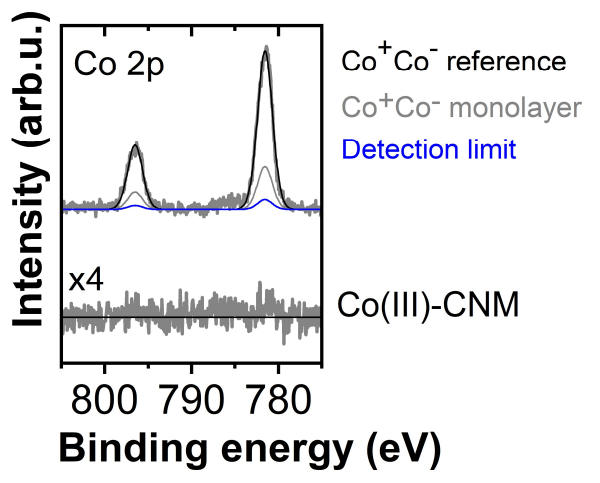

Figure S10. XP signals of the Co $2 \mathrm{p}$ region of the $\mathrm{Co}(\mathrm{III})-\mathrm{CNM}$ and $\mathrm{Co}^{+} \mathrm{Co}^{-}$-complex bulk reference scaled to monolayer and detection limit intensity. The calculated signal from a $\mathrm{Co}^{+} \mathrm{Co}^{-}$ monolayer is displayed in grey and the minimum detectable Co $2 \mathrm{p}_{3 / 2} \mathrm{XP}$ signal of $23 \%$ of a monolayer is shown in blue (both obtained by the respective scaling of the Co $2 \mathrm{p}$ signal measured from the bulk $\mathrm{Co}^{+} \mathrm{Co}^{-}$-complex sample).

The lowest detectable Co $2 \mathrm{p}_{3 / 2}$ signal is related to the signal-to-noise ratio (SNR) achievable in our experimental configurations. The standard deviation of the noise in the reference spectral region of 792-788 eV is 146 counts and a SNR of approximately 3:1 is necessary for the signal to be detectable and quantifiable. ${ }^{[17,18]}$ Knowing that the maximum signal intensity of the cobalt reference bulk signal (fit of the Co $2 p_{3 / 2}$ peak maximum of Figure 2 of the main manuscript) is $6950 \mathrm{kcts}$ one can conclude that the detectable minimum signal brought by the $3: 1$ criteria is $6 \%$ of the multilayer reference signal intensity (displayed in blue in Figure S10). This means, that the minimum detectable signal is $23 \%$ of the signal of a complex monolayer on top of the surface.

The monolayer is simulated assuming a square lattice model of upright standing cobalt units as depicted in Figure S9c. The mean complex area $A_{\text {mean, } \mathrm{Co}}$ of $0.40 \mathrm{~nm}^{2}$ is derived from the width and length of the complexes in Figure S9a. The lowest detectable signal of $23 \%$ of a monolayer leads therefore to a coverage density $\left(A_{C o}\right)$ of minimum 1 complex per $1.7 \mathrm{~nm}^{2}$ which corresponds to an average distance $\mathrm{d}_{\mathrm{Co}}$ (see Equation $\mathrm{S} 3$ ) between the complexes of $1.3 \mathrm{~nm}$ as the maximum detectable distance.

$$
d_{\text {unit }}=\sqrt{A_{\text {unit }}}=\sqrt{\frac{1}{N_{\text {unit }}\left[n m^{-2}\right]}}
$$

In other words, any surface number density lower than that would lead to a signal that is too low to be detected. Here, the Co(III)-CNM in Figure 2 of the main manuscript and Figure S10 
show a very weak signal for the binding energy assigned to Co $2 \mathrm{p}_{3 / 2}$, clearly at the limit of detection of the system. Thus, the average distance between complexes on the Co(III)-CNM is higher than $\sim 1.3 \mathrm{~nm}$. This general conclusion is further confirmed from the quantitative analysis of the nitrogen signal in section S.2.2. The detection of sub-monolayer Co $2 p$ signals was possible using angle resolved XPS. As demonstrated in Figure 11 on a simplified model system for $\mathrm{Co}^{+}$ immobilization on iso-CNMs the Co $2 p$ signal can be enhanced by increasing the emission angle and therewith increasing the surface sensitivity of XPS.
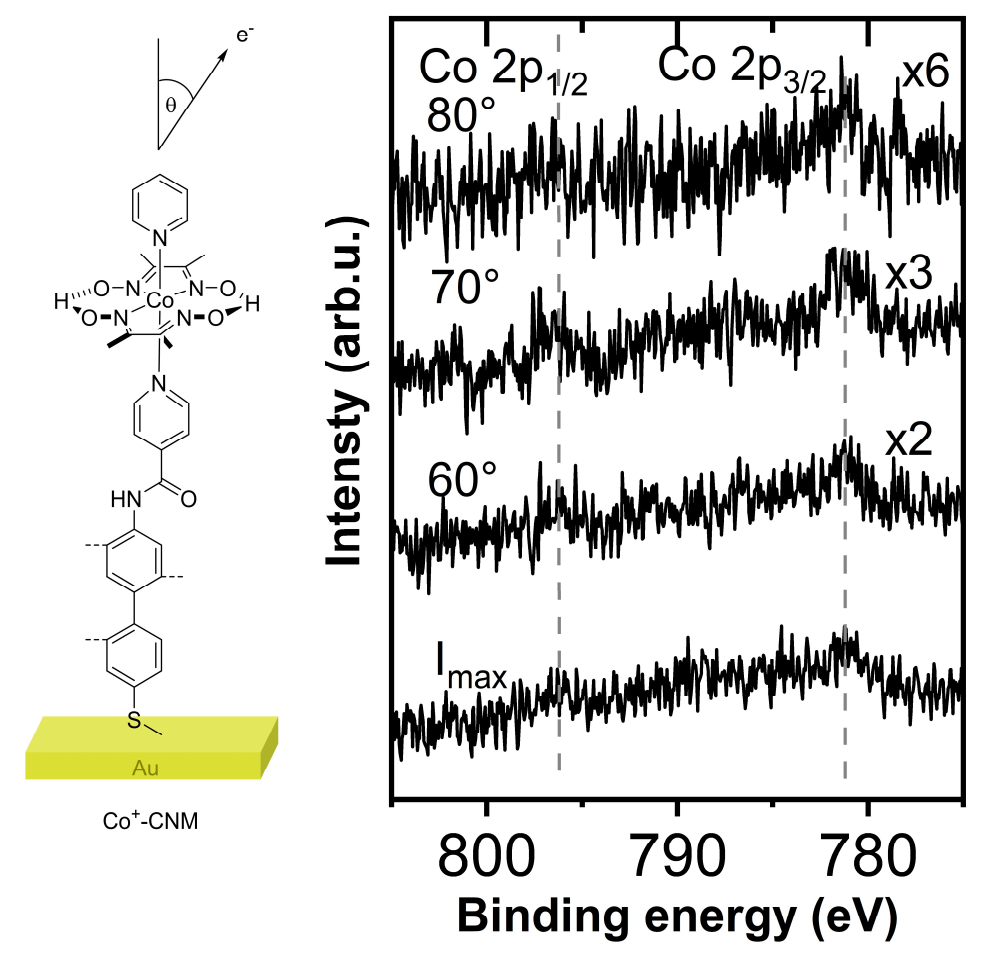

Figure S11. Angle-dependent XPS measurements in the spectral region of the Co $2 p$ signal performed on $[\mathrm{Co}(\mathrm{dmgh})(\mathrm{py}) \mathrm{Cl}]$ on iso-CNM. [Co(dmgh)(py)Cl] is used as a structurally identical, simplified $\mathrm{Co}^{+}$model system to investigate our capacity to locate the $\mathrm{Co}$ (III) atom in the membrane. Angle dependent XPS measurements show an increase in the Co $2 p$ signal with increasing the XP emission angle. The bottom row shows the spectrum obtained at an emission angle of $18.7^{\circ}$ corresponding to the intensity maximum $\mathrm{I}_{\max }$ used for standard XP measurements. The signals of Co $2 p_{1 / 2}$ at $796.3 \mathrm{eV}$ and Co $2 p_{3 / 2} 781.2 \mathrm{eV}$ can be identified above the noise level at larger emission angles implying that the Co atoms are located on the topmost part of the membrane. For better visibility the spectra are scaled by the shown magnification factors. Preparation conditions are the same as for Co(III)-CNM. 


\section{S.2.3. Estimation of Co-complex surface number density from $N$ 1s XPS signal}

Due to the extremely low SNR of the Co $2 p$ spectral region (Figure 2 of the main manuscript), quantification of the surface number density of the $\mathrm{Co}(\mathrm{III})$ complex double salt is carried out from the deconvolution of the $\mathrm{N}$ 1s signal. Moreover, the comparison of the ratios between between the nitrogen components allows a direct determination of functionalization degree $\alpha$ and the average number of molecular units per $\mathrm{nm}^{2} \mathrm{~N}_{\text {units }}$ as the number of amino groups on $\mathrm{NH}_{2}$-CNMs is known from previous investigations. ${ }^{[19]}$ Deconvolution was done in accordance to the literature and reference spectrum as schematized in Figure S12 (blue and orange deconvolution of Figure 2, $\mathrm{Co}(\mathrm{III})-\mathrm{CNM})$. The component in orange at $399.8 \mathrm{eV}$ is assigned to amide bonds and pyridines coordinated by hydrogen. The small shoulder at $400.9 \mathrm{eV}$ corresponds to the nitrogen ligand system surrounding the cobalt atoms as found in the bulk reference. Component areas are determined with large errors, estimated to $20 \%$, due to the low SNR of the components and the small observed shifts. The results of these calculations are summarized in Table S2.

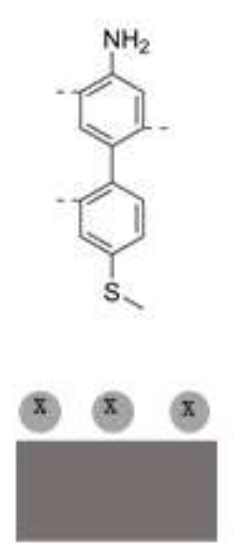

a) $\mathrm{NH}_{2}-\mathrm{CNM}$

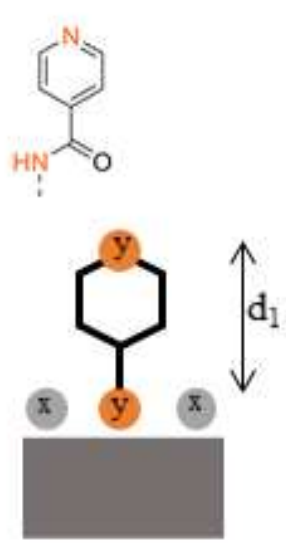

b) Iso-CNM

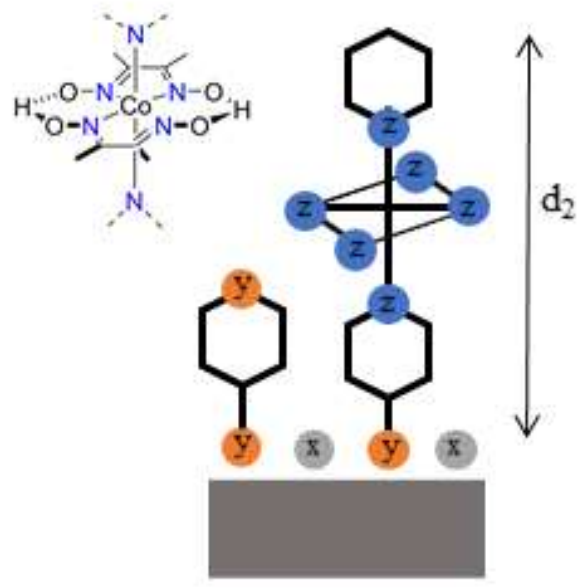

c) $\mathrm{Co}^{+} \mathrm{Co}^{-}-\mathrm{CNM}$

Figure S12. Scheme applied for the estimation of coverage density and functionalization degree based on the fits of the $\mathrm{N} 1 \mathrm{~s}$ signal of $\mathrm{NH}_{2}-\mathrm{CNM}$, iso-CNM and Co-CNM and $\mathbf{d}$ layer thicknesses used for calculation of the signal attenuation. $b$ ) In the iso-CNM the pyridine nitrogen atom on top is not attenuated. Whereas, the signal of unfunctionalized amine $\mathrm{x}$ and amide nitrogen atoms will be attenuated by $d_{1}$. c) For Co-CNM, the amine signal $\mathrm{x}$ will be attenuated by $d_{2}$ but the signals related to the nitrogen atoms nearby the Co(III) ion only by $1 / 2 d_{2} . d_{1}$ and $d_{2}$ where obtained according to the attenuation of the $\mathrm{Au} 4 \mathrm{f}_{7 / 2}$ signals of the respective samples. 
The surface number density of amino groups per $\mathrm{nm}^{2}$ on a $\mathrm{NH}_{2}-\mathrm{CNM}$ (Figure $\mathrm{S} 11 \mathrm{~A}$ ) is the basis of all calculations and distance estimations. Based on scanning tunneling microscopy and XPS results in the literature ${ }^{[19,20]}$, the area per molecule in NBPT SAMs ranges from $27.4 \AA^{2}$ to $48.5 \AA^{2}$ as NBPT SAMs have different phases. Therefore, the average number of amino groups $N_{\mathrm{NH}_{2}}$ in a $\mathrm{NH}_{2}-\mathrm{CNM}$ is $2.5 \pm 0.7 \mathrm{~nm}^{-2}$ under the assumption of $2.9 \pm 0.8 \mathrm{SAM}$ molecules per $1 \mathrm{~nm}^{2}$ and a reduction of nitrogen to $86 \pm 5 \%$ during low-energy electron irradiation. The distance between each $\mathrm{NH}_{2}$-group is $0.64 \pm 0.09 \mathrm{~nm}$ according to equation $\mathrm{S} 3$ if a square lattice model is applied for simplicity.

A functionalization degree $\alpha_{y}$ can be defined by the number of isonicotin molecules or amide groups $y$ in relation to the total number of amino groups on the $\mathrm{NH}_{2}-\mathrm{CNM}$. In the iso-CNM (Figure $\mathrm{S} 11 \mathrm{~b}$ ) the sum of amide $y$ and remaining amino groups $x$ is always equal to the number of amino groups in $\mathrm{NH}_{2}-\mathrm{CNMs}$. Therefore, the functionalization degree $\alpha_{y}$ of the iso-CNM can be defined in Equation S4:

$$
\alpha_{y}=\frac{y}{x+y}=\frac{\frac{y}{x}}{\frac{y}{x}+1}=1-\alpha_{x}
$$

$\alpha_{x}$ is therefore defined as the degree of unfunctionalized amines. The ratio between $y$ and $x$ can be calculated from the XP N 1s component area ratio between the unfunctionalized $-\mathrm{NH}_{2}$ groups ( $I_{x}$ corresponding to species $x$, Figure $\mathrm{S} 11 \mathrm{~B}$ ) and amide and pyridine nitrogen ( $I_{y}$ corresponding to orange species $y$, Figure S11B). Taking into account that $x$ and half of $y$ are attenuated by $d_{1}$, the ratio between the two component areas, based on Equation S1, reads as follows (inelastic mean free path $\lambda$ is $29 \AA$ for $N 1^{[16]}, d_{l}$ is $2 \AA$ as derived from the thickness difference of iso-CNM and $\left.\mathrm{NH}_{2}-\mathrm{CNM}\right)$ :

$$
\frac{I_{y}}{I_{x}}=\frac{y+y \cdot e^{-\frac{d_{1}}{\lambda \cos \theta}}}{x \cdot e^{-\frac{d_{1}}{\lambda \cos \theta}}}
$$

Therefore, the ratio between $\mathrm{y}$ and $\mathrm{x}$ can be expressed in Equation S5:

$$
\frac{y}{x}=\frac{I_{y}}{I_{x}} \cdot \frac{e^{-\frac{d_{1}}{\lambda \cos \theta}}}{1+e^{-\frac{d_{1}}{\lambda \cos \theta}}}=0.58 \pm 0.32 .
$$


A functionalization degree of $\alpha_{y}=37 \pm 13 \%$, as determined by Equation S6 and S4 successively, leads to the density of isonicotine molecules per $\mathrm{nm}^{2} N_{\text {isonicotin }}$ by using the average number of amino groups $\mathrm{N}_{\mathrm{NH}_{2}}$ in a $\mathrm{NH}_{2}$-CNM.

$$
N_{\text {isonicotin }}\left[\mathrm{nm}^{-2}\right]=\alpha_{y} \cdot N_{\mathrm{NH}_{2}}\left[\mathrm{~nm}^{-2}\right]=0.9 \pm 0.4\left[\mathrm{~nm}^{-2}\right]
$$

Based on Equation S3 the distance between each isonicotine molecule is therefore $1.1 \pm$ $0.2 \mathrm{~nm}$.

In $\mathrm{Co}$ (III)-CNM an additional component due to the ligand system surrounding the cobalt center ion is introduced in the XP N 1s spectrum (z-labeled nitrogen atoms in Figure S11C) coexisting with components assigned to $\mathrm{x}$ and $\mathrm{y}$. As the functionalization with $\mathrm{Co}(\mathrm{III})$ complexes does not change the amount of unreacted amino groups on the surface, $\alpha_{x}$ should remain the same as in the previous sample.

The coverage density of $\mathrm{Co}$ (III) complexes can be estimated comparing the components areas of amino groups to the nitrogen ligand system surrounding the cobalt atom (z-labeled nitrogen atoms in scheme S11C). A similar approach as for Equation S5 and S6 leads to Equation S8:

$$
\frac{I_{Z}}{I_{X}}=\frac{6 z \cdot e^{-\frac{d_{2}}{2 \lambda \cos \theta}}}{x \cdot e^{-\frac{d_{2}}{\lambda \cos \theta}}} .
$$

There, the signal of unfunctionalized amines is reduced by the thickness $d_{2}$ (thickness difference between the $\mathrm{NH}_{2}-\mathrm{CNM}$ and $\mathrm{Co}(\mathrm{III})-\mathrm{CNM}$ of $2 \AA$, Scheme S11). In contrast, the ligand system is attenuated only by $d_{2} / 2$ as it is located in the middle of this additional layer. The functionalization degree of cobalt complexes $\alpha_{z}$ in this sample is calculated by:

$$
\alpha_{z}=\frac{z}{\frac{x}{\alpha_{x}}}=\frac{I_{z}}{I_{x} \cdot 6} \cdot e^{-\frac{d_{2}}{2 \lambda c o}} \cdot\left(1-\alpha_{y}\right)=4 \pm 1 \%
$$

We have therefore a coverage density of $4 \pm 1 \%$ of complex molecules on the surface $N_{C o}$, corresponding according to equation $\mathrm{S} 7$ to $0.09 \pm 0.04 \mathrm{Co}$ (III) complexes per $\mathrm{nm}^{2}$ and an average distance between each Co complex $k_{C o}$ of $3.4 \pm 0.8 \mathrm{~nm}$ according to equation $\mathrm{S} 3$. The area which is covered by one complex molecule is therefore $11.3 \pm 5.0 \mathrm{~nm}^{2}$ which equals to $4 \%$ of a monolayer using the mean area for one complex of $0.40 \mathrm{~nm}^{2}$. Therewith, it follows that this coverage is below the detection limit, showing that both models using two different XP signals, 
Co $2 \mathrm{p}_{3 / 2}$ and $\mathrm{N} 1 \mathrm{~s}$, agree well with each other. We can therefore use the average distance $k_{C o}$ between each cobalt complex of $3.4 \pm 0.8 \mathrm{~nm}$ as a starting point for designing the TERS experimental conditions. 
Table S2. Summary of the values used and obtained for calculating the coverage density of cobalt complexes and isonicotin molecules on the CNMs. The areas and positions of the compared N $1 \mathrm{~s}$ components $I$ in the CNMs are shown as well as the thickness increase $d$ between $\mathrm{NH}_{2}-\mathrm{CNM}$ and iso-CNM $\left(d_{1}\right)$ or $\mathrm{Co}(\mathrm{III})-\mathrm{CNM}\left(d_{2}\right)$, respectively. The functionalization degree $\alpha$ with the respective molecules compared to the initial number of amino groups on the $\mathrm{NH}_{2}-\mathrm{CNM}$ was calculated as shown above, as well as the average number of molecules per $\mathrm{nm}^{2} N$ and the average distance between each of the molecules $k$.

\begin{tabular}{|c|c|c|c|c|c|c|}
\hline Sample & $\begin{array}{l}\text { Component } \\
[\mathrm{eV}]) \text {, intens }\end{array}$ & $\begin{array}{l}\text { inding energy } \\
\text { [arb.u.]) }\end{array}$ & $\boldsymbol{d}[\AA]$ & $\alpha$ & $N\left[\mathrm{~nm}^{-2}\right]$ & $k[\mathrm{~nm}]$ \\
\hline $\mathrm{NH}_{2}-\mathrm{CNM}$ & $\begin{array}{l}\mathrm{x}\left(-\mathrm{N}_{\mathrm{NH} 2}\right) \\
398.9 \mathrm{eV}\end{array}$ & - & 0 & 0 & $2.5 \pm 0.7$ & $0.6 \pm 0.09$ \\
\hline Iso-CNM & $\begin{array}{l}\mathrm{x}\left(-\mathrm{N}_{\mathrm{NH} 2}\right) \\
399.0 \mathrm{eV} \\
51 \pm 10 \text { arb.u. }\end{array}$ & $\begin{array}{l}\mathrm{y} \quad\left(\mathrm{N}_{\text {pyridine}},\right. \\
\text { amide }) \\
399.8 \mathrm{eV} \\
61 \pm 12 \text { arb.u. }\end{array}$ & $\mathrm{d}_{1}=2 \AA$ & $\alpha_{\mathrm{y}}=37 \pm 13 \%$ & $0.9 \pm 0.4$ & $1.1 \pm 0.2$ \\
\hline $\begin{array}{l}\text { Co(III)- } \\
\text { CNM }\end{array}$ & $\begin{array}{l}x\left(-\mathrm{N}_{\mathrm{NH} 2}\right) \\
399.0 \mathrm{eV} \\
79 \pm 16 \text { arb.u. }\end{array}$ & $\begin{array}{l}\mathrm{z}\left(\mathrm{N}_{\mathrm{Co}(\mathrm{III})}\right) \\
400.9 \\
28 \pm 6 \text { arb.u. }\end{array}$ & $\mathrm{d}_{2}=2 \AA$ & $\alpha_{z}=4 \pm 1 \%$ & $0.09 \pm 0.04$ & $3.4 \pm 0.8$ \\
\hline
\end{tabular}




\section{Section S4. TERS surface number density investigation.}

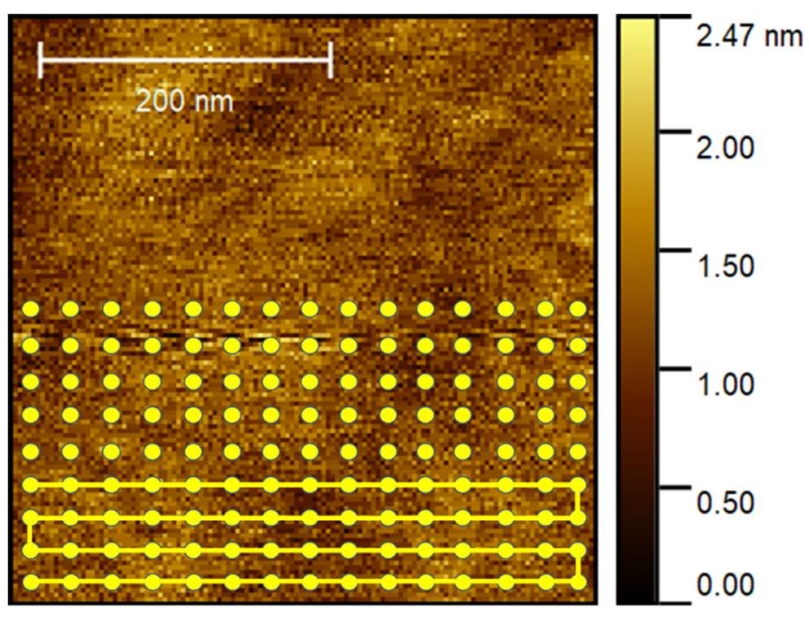

Figure S13. Example of an AFM image of a $400 \times 400 \mathrm{~nm}$ region of a CNM, transferred on an ultra-thin (10 nm thick) gold surface, whose root mean square roughness of $430 \mathrm{pm}$ is in accordance to literature. ${ }^{[19]}$ Yellow circles with a point-to-point distance of $25 \mathrm{~nm}$ represent locations where the tip has been located for TERS measurements.

The exact spatial resolution in TERS is experiment dependent, tip dependent and is still subject to debate. ${ }^{[21]}$ Several studies of our research group have shown experimentally and theoretically that the spatial resolution achieved with use of our TERS tips should be on the order of the nanometer scale. ${ }^{[21-24]}$ In the context of this study, we have purposely applied undersampling (point-to-point distance between measurement of $25 \mathrm{~nm}$ - see Figure S13) to gain information on the real surface distribution of chemical species. Even in this context, the surface number density can be found by using simple statistical rational, as shown in Figure S14, where conclusions on surface number density depend on the lateral resolution of TERS vs. the molecule-to-molecule distance.

For the purpose of this demonstration, we conservatively assume a low lateral resolution of $\sim 3$ $\mathrm{nm}$ (dashed circles of Figure S14) and assume a molecule-to-molecule distance of $4.5 \mathrm{~nm}$ (Figure 
S14,a), knowing that the diameter occupied by the isonicotine molecules attached on the surface is approximately $1 \mathrm{~nm}$ (blue circles of Figure S14), a scan with $1.5 \mathrm{~nm}$ step size would consequently not miss isonicotinic acid. However, at this distance and given the above-mentioned resolution and step size parameters when the tip is positioned, e.g., exactly between $4.5 \mathrm{~nm}$ spaced isonicotinic acid molecules, no signal would be measured. Furthermore, a variation of the signal intensity depending on the exact location of the molecule with respect to the tip would be detected.The Figure S14b shows another scenario where the molecule-to-molecule distance is 3 $\mathrm{nm}$. Keeping the lateral resolution of TERS constant at $3 \mathrm{~nm}$, the signal can still vary, however, isonicotinic acid will be always probed. Any smaller molecule-to-molecule distance would also lead to a comparatively constant point-to-point signal amplitude. Here, the systematic probing of a similar signal intensity in Figure $3 \mathrm{c}$ of the main manuscript matches well with the XPS analysis showing an isonicotine to isonicotine distance of $\sim 1 \mathrm{~nm}$. The actual experiment did not use the step sizes shown in S14, but a step size between TERS spots of $25 \mathrm{~nm}$. While a direct resolution cannot be assessed, nevertheless, the number of positions addressed with the TERS experiments allows to draw several conclusions. The fact that almost no signal intensity variation was observed, either points to a very homogeneous surface or to a low resolution TERS tip. The latter can be excluded, as the band position fluctuations can be considered as a strong indication of a sampling of non-averaged ensembles ( $\ll 100$ molecules). Consequently, as mentioned already above, the $3 \mathrm{~nm}$ lateral resolution is the upper limit. This leaves us with an estimation of the spacing of isonicotinic acid molecules of less than $3 \mathrm{~nm}$, most likely even below $2 \mathrm{~nm}$ so well in the regime of the XPS results. 
a Top view: molecule-to-molecule distance of $4.5 \mathrm{~nm}$

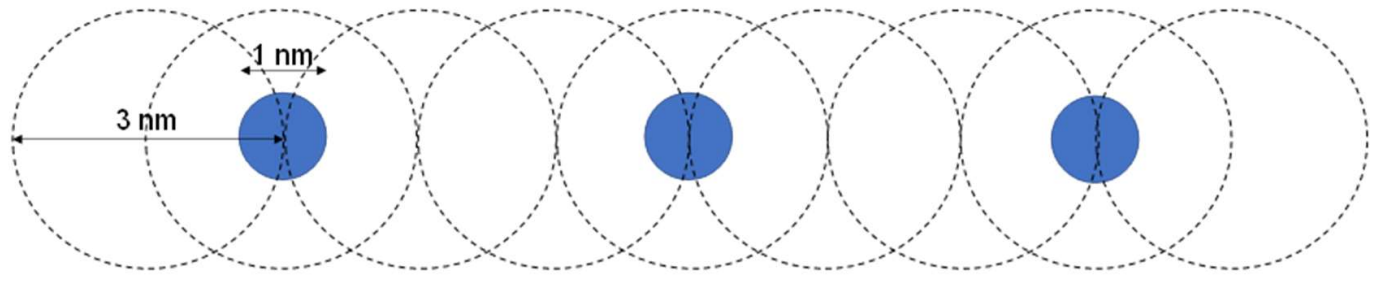

b Top view: molecule-to-molecule distance of $3 \mathbf{~ n m}$

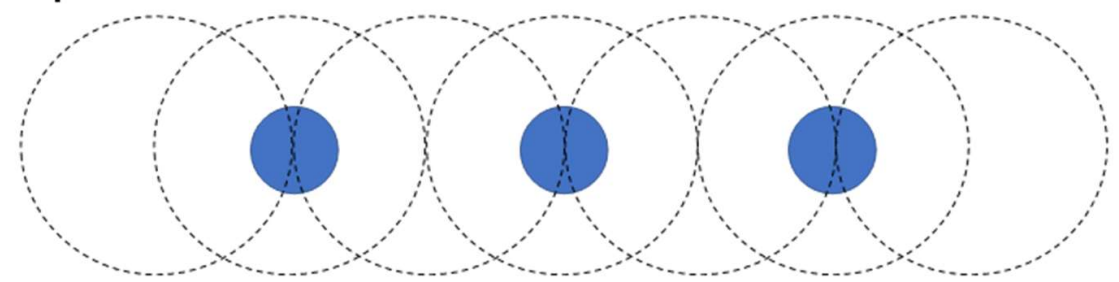

Figure S14. a) Top view of a scheme exposing TERS spatial resolution postulated as $3 \mathrm{~nm}$ or lower (dashed circles) vs molecule-to-molecule distance of $4.5 \mathrm{~nm}$ and b) of $3 \mathrm{~nm}$ for an isonicotine molecule (blue circles) at the surface of a $\mathrm{NH}_{2}-\mathrm{CNM}$ membrane. In the top scenario, the TERS signal would statistically vary from point to point while it remains approximately constant in the bottom scenario. 
Section S5. Raman spectroscopy investigation of the $\mathrm{Co}^{+} \mathrm{Co}^{-}$double salt complex.

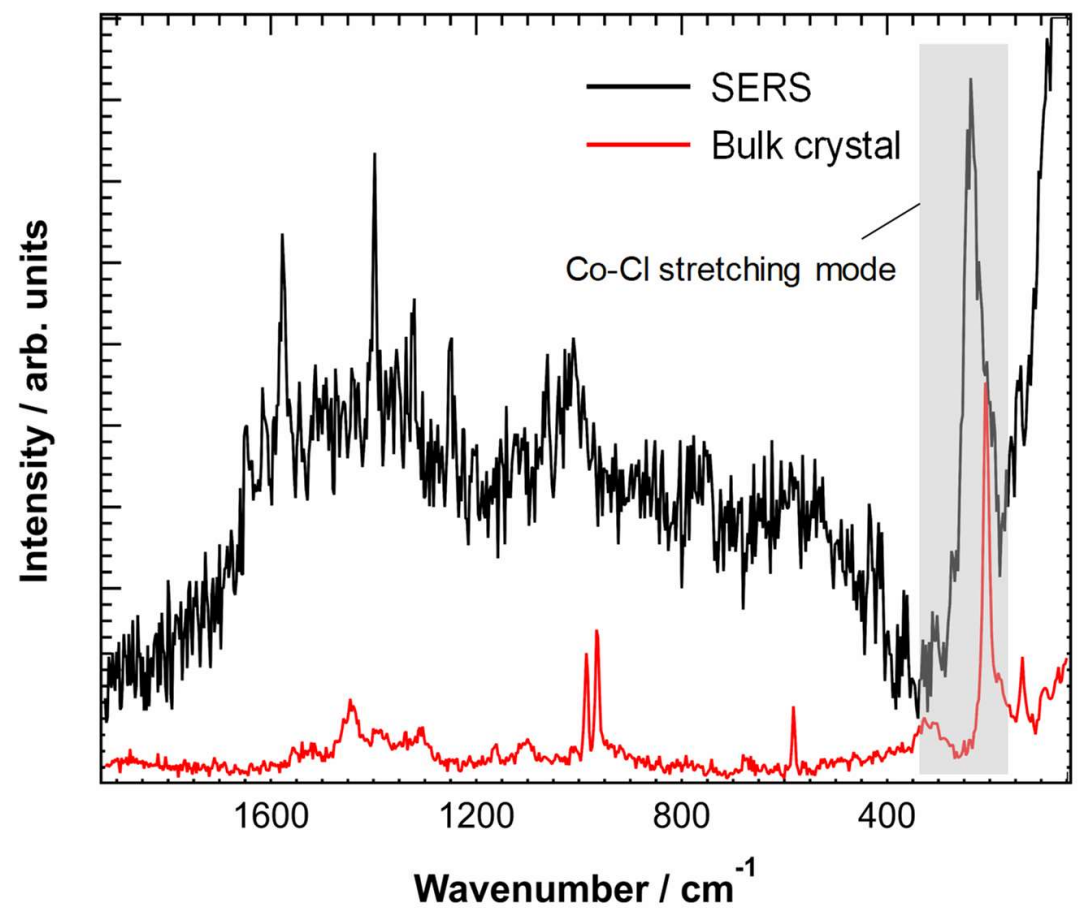

Figure S15. Comparison of the SERS and bulk crystal spectra of the $\mathrm{Co}^{+} \mathrm{Co}^{-}$double salt complex. SERS measurements were conducted at a power of $\sim 1 \mu \mathrm{W}$ to avoid the burning of the sample. Grey highlight shows the band attributed to $\mathrm{Co}-\mathrm{Cl}$ stretching, that is absent from the TERS data shown in Figure 3d of the main text. 
Section S6. TERS investigation of the $\mathrm{Co}^{+} \mathrm{Co}^{-}$double salt complex immobilization.

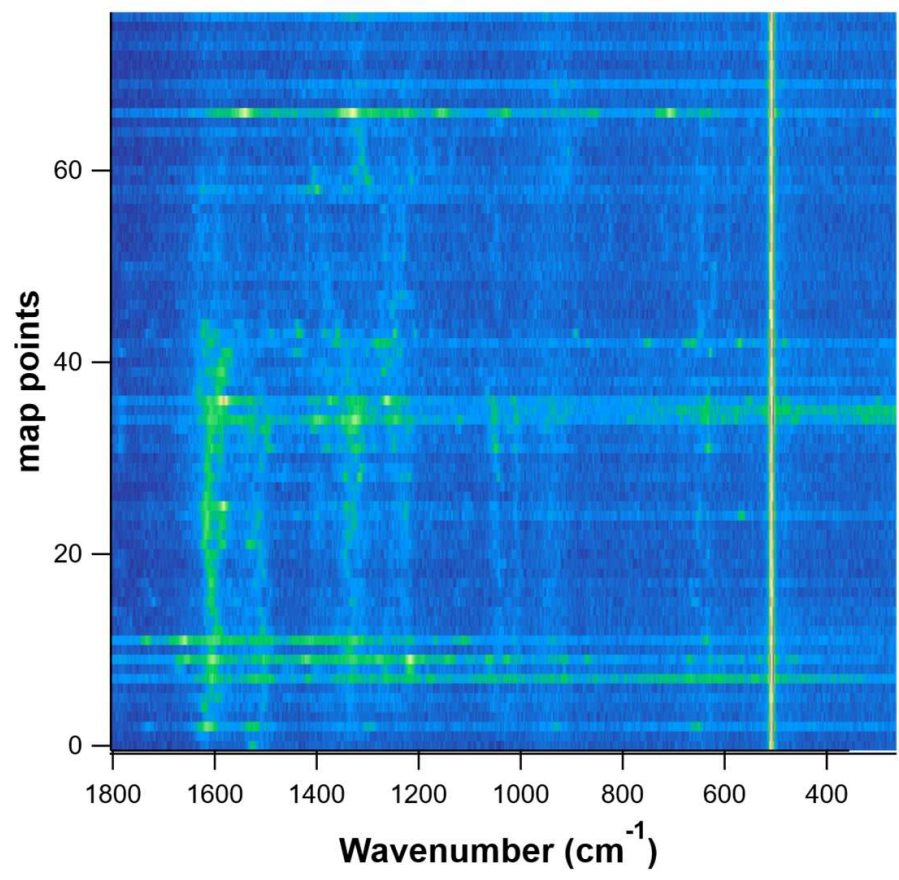

Figure S16. Waterfall plot of a series of TERS spectra measured on a CMN surface on which the Co(III) complex has been immobilized. Band position and fluctuation as a function of time are similar to that of Figure $3 \mathrm{~d}$ revealing reproducibility of the TERS results at different positions using a different tip. 


\section{References}

[1] W. Eck; V. Stadler; W. Geyer; M. Zharnikov; A. Gölzhäuser; M. Grunze, Adv. Mater. 2000, 12 (11), 805.

[2] A. Turchanin; A. Tinazli; M. El-Desawy; H. Großmann; M. Schnietz; H. H. Solak; R. Tampé; A. Gölzhäuser, Adv. Mater. 2008, 20 (3), 471.

[3] P. Angelova; H. Vieker; N.-E. Weber; D. Matei; O. Reimer; I. Meier; S. Kurasch; J. Biskupek;

D. Lorbach; K. Wunderlich; L. Chen; A. Terfort; M. Klapper; K. Müllen; U. Kaiser; A. Gölzhäuser; A. Turchanin, ACS Nano 2013, 7 (8), 6489.

[4] L. Langelüddecke; P. Singh; V. Deckert, Appl. Spectrosc. 2015, 69 (12), 1357.

[5] A. Beyer; A. Godt; I. Amin; C. T. Nottbohm; C. Schmidt; J. Zhao; A. Gölzhäuser, Phys. Chem. Chem. Phys. 2008, 10 (48), 7233.

[6] Y. Zubavichus; M. Zharnikov; Y. Yang; O. Fuchs; E. Umbach; C. Heske; A. Ulman; M. Grunze, Langmuir 2004, 20 (25), 11022.

[7] P. M. Dietrich; C. Streeck; S. Glamsch; C. Ehlert; A. Lippitz; A. Nutsch; N. Kulak; B. Beckhoff; W. E. S. Unger, Anal. Chem. 2015, 87 (19), 10117.

[8] N. M. Muresan; J. Willkomm; D. Mersch; Y. Vaynzof; E. Reisner, Angew. Chem. Int. Ed. Engl. 2012, 51 (51), 12749.

[9] A. M. Beiler; D. Khusnutdinova; S. I. Jacob; G. F. Moore, Ind. Eng. Chem. Res. 2016, 55 (18), 5306.

[10] K. C. Dash; B. Folkesson; R. Larsson; M. Mohapatra, J. Electron. Spectrosc. Relat. Phenom. 1989, 49 (3), 343.

[11] J. Scherr; Z. Tang; M. Küllmer; S. Balser; A. S. Scholz; A. Winter; K. Parey; A. Rittner; M. Grininger; V. Zickermann; D. Rhinow; A. Terfort; A. Turchanin, ACS Nano 2020, 14 (8), 9972.

[12] A. Turchanin; D. Käfer; M. El-Desawy; C. Wöll; G. Witte; A. Gölzhauser, Langmuir 2009, 25 (13), 7342.

[13] G. García-Herbosa; W. R. McNamara; W. W. Brennessel; J. V. Cuevas; S. Sur; R. Eisenberg, Polyhedron 2013, 58, 39.

[14] S. Martin; C. Revathi; A. Dayalan, J. Chem. Crystallogr. 2009, 39 (12), 908.

[15] D. Briggs; M. P. Seah, Auger and x-ray photoelectron spectroscopy. 2. ed.; Wiley: Chichester, 1990. 
[16] C. J. Powell; A. Jablonski, NIST Electron Inelastic-Mean-Free-Path Database. National Institute of Standards and Technology: Gaithersburg, MD, 2010; Vol. Version 1.2.

[17] S. Hofmann, Auger- and X-ray photoelectron spectroscopy in materials science : a useroriented guide. Springer: Berlin ; Heidelberg ; New York ; Dordrecht ; London, 2013.

[18] P. J. Cumpson; M. P. Seah, Surf. Interface Anal. 1992, 18 (5), 361.

[19] C. Neumann; R. A. Wilhelm; M. Küllmer; A. Turchanin, Faraday Discuss. 2021, 227 (0), 61.

[20] H. Kampmann. Über das Wachstum und die Struktur Selbstorganisierender Monolagen. Dissertation, University Bielefeld, 2014.

[21] M. Richard-Lacroix; Y. Zhang; Z. Dong; V. Deckert, Chem. Soc. Rev. 2017, 46 (13), 3922.

[22] M. Richard-Lacroix; V. Deckert, Light Sci. Appl. 2020, 9, 35.

[23] T. Deckert-Gaudig; E. Kämmer; V. Deckert, J. Biophotonics 2012, 5 (3), 215.

[24] S. Trautmann; J. Aizpurua; I. Götz; A. Undisz; J. Dellith; H. Schneidewind; M. Rettenmayr; V. Deckert, Nanoscale 2017, 9 (1), 391. 